\title{
Survey of Radiator Temperatures in Buildings Supplied by District Heating
}

Master's thesis in the Sustainable Energy Systems Program

MARIA JANGSTEN

Department of Civil and Environmental Engineering

Division of Building Services Engineering

CHALMERS UNIVERSITY OF TECHNOLOGY

Master's Thesis BOMX02-16-83

Gothenburg, Sweden 2016 



\title{
Survey of Radiator Temperatures in Buildings Supplied by District Heating
}

\author{
Master's Thesis in the Master's Program Sustainable Energy Systems \\ MARIA JANGSTEN
}

SUPERVISOR:

Johan Kensby

EXAMINER:

Jan-Olof Dalenbäck

Department of Civil and Environmental Engineering

Division of Building Services Engineering

CHALMERS UNIVERSITY OF TECHNOLOGY

Gothenburg, Sweden 2016 
Survey of Radiator Temperatures in Buildings Supplied by District Heating Master's Thesis in the Master's Program Sustainable Energy Systems MARIA JANGSTEN

(C) MARIA JANGSTEN, 2016

Examensarbete BOMX02-16-83 / Institutionen för bygg- och miljöteknik, Chalmers tekniska högskola 2016

Department of Civil and Environmental Engineering Division of Building Services Engineering Chalmers University of Technology SE-412 96 Gothenburg

Sweden

Telephone: + 46 (0) 31-772 1000

Department of Civil and Environmental Engineering.

Göteborg, Sweden 2016 
Survey of Radiator Temperatures in Buildings Supplied by District Heating

Master's Thesis in the Sustainable Energy Systems program

MARIA JANGSTEN

Department of Civil and Environmental Engineering

Division of Building Services Engineering

Chalmers University of Technology

\section{ABSTRACT}

In order to maintain the competitiveness and improve the environmental performance of district heating in the future it may be of essence to transition to lower operating temperatures over those of the current third generation district heating systems. This is due to the fact that heat demands are expected to decrease as buildings become more energy efficient as well as new types of heat sources are likely to be integrated. The third generation district heating systems operate at annual average temperatures of 75$90^{\circ} \mathrm{C}$ supply and $40-50^{\circ} \mathrm{C}$ return in Sweden today. However, these temperatures are well above the customer temperature demands which are to heat buildings to approximately $20^{\circ} \mathrm{C}$ and provide domestic hot water at $50^{\circ} \mathrm{C}$. Therefore, future supply and return temperatures of $50-55 / 20-30^{\circ} \mathrm{C}$ for the next fourth generation district heating systems have been suggested.

Radiators in buildings constructed prior to the 1980's have in Sweden typically been designed for supply temperatures of $80^{\circ} \mathrm{C}$ to provide space heating. However, as buildings are renovated, this temperature must be lowered to avoid overheating. For buildings constructed subsequent to 1982 the radiator design supply temperature should be a maximum of $60^{\circ} \mathrm{C}$. Several previous studies have established what the temperatures on the primary side of the district heating systems are, however there is a lack of documentation on the temperatures of the secondary side. The purpose of this project is therefore to investigate the radiator temperatures on the district heating secondary side.

In this research project, data for 109 radiator systems for multi-family dwellings in the city of Gothenburg, Sweden, has been analyzed. Supply and return temperatures for the design outdoor temperature have been calculated based upon available data measurements for one year. Factors affecting the operating temperatures of the radiators, such as radiator size and hydronic balancing, have also been examined.

The results show that the average supply and return temperatures for the design outdoor temperature of $-16^{\circ} \mathrm{C}$ are 64 and $42^{\circ} \mathrm{C}$ respectively. The radiator sizes were shown to be decreasing with increasing supply temperatures, where the largest potential of lowering the radiator operating temperatures were found in the systems with a large radiator size and a lower specific space heating demand. For an outdoor temperature of $5^{\circ} \mathrm{C}$ and above all radiator systems operate with supply temperatures less than $55^{\circ} \mathrm{C}$.

Key words: Radiator temperatures, Low-temperature district heating, 4GDH, Existing buildings, Radiator sizes 
Kartläggning av radiatortemperaturer i byggnader med fjärrvärme

Examensarbete inom mastersprogrammet Hållbara Energisystem

MARIA JANGSTEN

Institutionen för Bygg- och Miljöteknik

Avdelningen för Installationsteknik

Chalmers tekniska högskola

\section{SAMMANFATTNING}

För att fjärrvärme skall fortsätta vara konkurrenskraftigt $\mathrm{i}$ framtiden, samt för att minimera dess miljöpåverkan kan en övergång till lägre temperaturer än de som den nuvarande tredje generationen innebär vara en viktig del i utvecklingen. Detta är bland annat för att byggnaders värmebehov förväntas minska då de blir mer energieffektiva samtidigt som nya typer av värmekällor skall kunna integreras i fjärrvärmenätet. Den tredje generationens fjärrvärmesystem har i Sverige idag framledningstemperaturer, baserat på årliga medelvärden, på $75-90^{\circ} \mathrm{C}$, samt returledningstemperaturer på $40-50^{\circ} \mathrm{C}$. Dock är dessa värden betydligt högre än vad kundernas slutliga behov uppgår till, vilket är att värma upp inomhusluften i byggnaderna till ca $20^{\circ} \mathrm{C}$, samt att värma tappvarmvattnet till $50-60^{\circ} \mathrm{C}$. Fram- och returtemperaturerna för nästa, fjärde generationens fjärrvärme, har därför förslagits vara omkring $50-55 / 20-30^{\circ} \mathrm{C}$.

I Sverige har radiatorer i byggnader som byggdes innan 1980 vanligtvis varit designade för framledningstemperaturer på $80^{\circ} \mathrm{C}$, men allt eftersom renoveringar genomförs måste temperaturerna sänkas för att undvika överhettning. I byggnader som byggdes efter 1982 skall den dimensionerande framledningstemperaturen vara $60^{\circ} \mathrm{C}$ enligt byggnadsreglerna. Flera studier har tidigare dokumenterat temperaturerna på primärsidan i fjärrvärmesystemen, men däremot är information om temperaturerna på sekundärsidan mer otillgänglig. Syftet med den här studien är därför att kartlägga radiatortemperaturerna på sekundärsidan i fjärrvärmesystemet.

I den här studien har data från 109 radiatorsystem i flerbostadshus i Göteborg sammanställts och analyserats. Fram- och returledningstemperaturer för den dimensionerande utomhustemperaturen har beräknats baserat på tillgänglig data uppmätt under ett år. Faktorer som påverkar radiatortemperaturerna, så som radiatorstorlek och injustering av systemen, har också undersökts.

Resultaten visade att medelvärdet för fram- och returledningstemperaturerna är 64 och $42^{\circ} \mathrm{C}$ för den dimensionerande utomhustemperaturen, vilken är $-16^{\circ} \mathrm{C}$ i Göteborg. Radiatorstorlekarna visades minska med ökande framledningstemperaturer, där den största potentialen att sänka temperaturerna återfanns $\mathrm{i}$ de system som hade stora radiatorer och tillhörde en byggnad med ett lägre specifikt värmebehov. Vid en utetemperatur av $5^{\circ} \mathrm{C}$ eller mer har alla radiatorsystem kartlagda $\mathrm{i}$ studien en framledningstemperatur på $55^{\circ} \mathrm{C}$ eller mindre.

Nyckelord: radiatortemperaturer, lågtemperaturssystem, 4GDH, befintliga byggnader, radiatorstorlekar 


\section{Contents}

ABSTRACT I

SAMMANFATTNING II

CONTENTS III

PREFACE $\quad$ V

$\begin{array}{lll}\text { ABBREVIATIONS } & \text { VII }\end{array}$

1 INTRODUCTION 1

1.1 Previous Work 2

1.2 Purpose 2

1.3 Scope \& Objective 3

2 THEORY 5

2.1 District Heating 5

2.1.1 Substations 5

2.1.2 Temperature Levels in the District Heating System 6

2.1.3 Capacities in the District Heating System 8

2.1.4 Temperature Difference Across Heat Exchanger 8

2.2 Radiator Space Heating Systems 9

$\begin{array}{ll}2.2 .1 & \text { Radiator Design }\end{array}$

2.2.2 Radiator Sizes 11

$\begin{array}{ll}2.2 .3 & \text { Radiator Design Temperatures }\end{array}$

$\begin{array}{lll}2.2 .4 & 13\end{array}$

$\begin{array}{lll}\text { 2.2.5 Radiator Control and Monitoring } & 14\end{array}$

3 SURVEY METHOD 17

$\begin{array}{lll}3.1 \quad \text { Data Collection } & 17\end{array}$

$\begin{array}{ll}\text { 3.1.1 Categorization of Geographical Areas } & 17\end{array}$

3.1.2 Calculation of Supply and Return Temperatures at DOT 18

3.2 Potential Factors Affecting the Temperature Levels 19

4 RESULTS $\quad 21$

4.1 Results from Data Analysis of Collected Data 21

4.2 Radiator System Temperatures 23

4.2.1 Temperature Difference in the Radiator Systems 26

4.3 Factors Affecting the Radiator Temperatures 29

$\begin{array}{ll}\text { 4.3.1 Radiator Sizes } & 29\end{array}$

4.3.2 Building Construction Year 31

4.3.3 Building Specific Space Heating Demand 32

4.3.4 Hydronic Balancing of Radiator Systems 33

4.4 Temperatures on the Primary Side of the DH System 34 
5 DISCUSSION 39

5.1 Potential Temperature Reduction in the existing DH System 39

5.2 Future DH Temperature Level Evaluation 40

$5.3 \quad$ Validation of Results 41

5.4 Future Work 43

6 CONCLUSION 45

7 REFERENCES 


\section{Preface}

In this master's thesis a survey of the radiator temperatures in existing buildings supplied by district heating has been done. Potential factors affecting the temperature levels have also been investigated and evaluated. The project was conducted at the Division of Building Services Engineering at Chalmers University of Technology, in cooperation with the public housing company Bostads AB Poseidon.

I wish to thank my supervisor Johan Kensby for his support during this work and always dedicating time to answer my questions. I would like to express my gratitude to my examiner Jan-Olof Dalenbäck at Chalmers University of Technology as well as Rolf Klarin and Andreas Hansson at Bostads AB Posidon for making this study possible, as well as dedicating time to provide guidance, crucial for the progress of this work. Additionally, I would also like to thank Anders Trüschel at Chalmers University of Technology and Otto Olsson at Göteborg Energi AB for valuable input, as well as Sven Werner for the idea behind this study.

Göteborg, June 2016

Maria Jangsten 


\section{Nomenclature}

\section{Roman upper case letters}

A Heat transfer area $\left[\mathrm{m}^{2}\right]$

$A_{\text {system }} \quad$ Overall heat transfer area for the radiator system $\left[\mathrm{m}^{2}\right]$

$K_{\text {rad }} \quad$ Radiator constant $\left[\mathrm{W} / \mathrm{K}^{\mathrm{n}}\right]$

$K_{\text {rad,system }}$ Overall radiator constant for radiator system [W/K $\left./ \mathrm{K}^{\mathrm{n}}\right]$

$K_{r a d, n} \quad$ Normalized radiator constant $\left[\mathrm{W} / \mathrm{K}^{\mathrm{n}} \mathrm{m}^{2}\right]$

$T_{\text {out }} \quad$ Outdoor temperature

$T_{D H, s} \quad$ District heating primary side supply temperature

$T_{D H, r} \quad$ District heating primary side return temperature

$T_{\text {rad,s }} \quad$ Radiator supply temperature

$T_{\text {rad, } r} \quad$ Radiator return temperature

$\dot{Q} \quad$ Thermal power transferred [W]

$\dot{Q}_{\text {rad }} \quad$ Thermal power output from radiator [W]

$Q_{S H} \quad$ Building yearly specific space heating demand [W]

$U \quad$ Coefficient of thermal transmittance $\left[\mathrm{W} / \mathrm{m}^{2} \mathrm{~K}\right]$

\section{Roman lower case letters}

$n \quad$ Radiator exponent [-]

$\Delta t_{l n} \quad$ Logarithmic mean temperature difference between hot and cold flows [K]

$\Delta t_{D H} \quad$ Temperature difference on the district heating primary side $\left[{ }^{\circ} \mathrm{C}\right]$

$\Delta t_{H E X} \quad$ Temperature difference across heat exchanger between primary and secondary sides $\left[{ }^{\circ} \mathrm{C}\right]$

$\Delta t_{S H} \quad$ Temperature difference between radiator supply and return $\left[{ }^{\circ} \mathrm{C}\right]$

$t_{w, \text { in }} \quad$ Radiator supply temperature $\left[{ }^{\circ} \mathrm{C}\right]$

$t_{w, \text { out }} \quad$ Radiator return temperature $\left[{ }^{\circ} \mathrm{C}\right]$

$t_{\text {room }} \quad$ Room temperature $\left[{ }^{\circ} \mathrm{C}\right]$ 


\section{Abbreviations}

$3 G D H \quad$ Third Generation District Heating

$4 G D H \quad$ Fourth Generation District Heating

BETSI Byggnaders Energi, Teknisk Status och Inomhusmiljö (The Energy Use in Buildings, Technical Status and Indoor Climate)

DH District Heating

DHW Domestic Hot Water

DCW Domestic Cold Water

DOT Design Outdoor Temperature

HEX Heat Exchanger

LTDH Low Temperature District Heating

SCADA Supervisory Control and Data Acquisition

SH Space Heating 



\section{Introduction}

District heating $(\mathrm{DH})$ is a well-established heat distribution technology utilizing a relatively cheap energy source to generate heat which is supplied through a network of distribution pipes to its customers. The generation side of the DH system is referred to the as the primary side and the customer side as the secondary side. District heating was initially introduced in the late nineteenth century in the United States and has since developed, mainly by introducing new heat sources and lowering the operating temperatures. The development of district heating can be categorized into different generations where the first generation utilized steam as the heat carrier. The second generation district heating transitioned to pressurized hot water as the heat carrier with temperatures of well above $100^{\circ} \mathrm{C}$. The most common district heating technology in operation today is labeled the third generation (3GDH) and the temperatures are typically less than $100^{\circ} \mathrm{C}$ (Frederiksen \& Werner, 2013).

The most common customers connected to the DH system are residential buildings where the $\mathrm{DH}$ is used to provide heat to the secondary side by means of a heat exchanger (HEX). The secondary side is composed of space heating $(\mathrm{SH})$ and domestic hot water (DHW) systems for the residents. The terminal heat emitting units most frequently used in residential SH systems are hydronic radiators (Johansson, 2011). Other heat emitters such as fan coils and convectors also exist. Depending on the building's characteristics it has a certain heat demand, which can be expressed as a specific heat demand per square meter of heated surface area and year. The specific heat demand varies from more than $200 \mathrm{kWh} / \mathrm{m}^{2} \mathrm{yr}$ down to $50 \mathrm{kWh} / \mathrm{m}^{2} \mathrm{yr}$ for different residential buildings, not including low or net zero energy buildings. Separated from the heat demand are the temperature levels of the SH and DHW systems, where two buildings with the same heat demand may have different temperature demands for the $\mathrm{SH}$ system. The indoor room temperature in residences must be a minimum of $18^{\circ} \mathrm{C}$, but it is usually kept around $21^{\circ} \mathrm{C}$. Different temperature levels of the $\mathrm{SH}$ water can achieve this, and it is the design and operation of the building's prevailing radiator system that will determine the achieved SH water temperatures. For the supply of DHW, temperatures of less than $60^{\circ} \mathrm{C}$ are required to avoid scalding, but have to be greater than $50^{\circ} \mathrm{C}$ to avoid growth of the bacteria legionella (Boverket, 2002).

Buildings in the existing stock have traditionally been designed for SH system supply temperatures of $60-80^{\circ} \mathrm{C}$, however these temperatures may not necessarily still exist in the systems (Wollerstrand, Ljunggren, \& Johansson, 2007). For example, when a building undergoes a renovation the heat demand typically decreases, and so does the temperature levels in the SH system in order to avoid overheating. It is also common that the radiator surfaces present in the existing building stock have been over dimensioned to ensure a safety margin, something which also allows for a lowering of the radiator temperatures (Lauenburg \& Wollerstrand, 2014).

The DH technology has since it was first introduced undergone different stages of development as well as efficiency improvements, where each generation has been state of the art for approximately 40-50 years (Lauenburg, 2016). The current joint efforts, among others within the European Union, to eliminate the negative environmental impacts from heat and power generation are strongly influencing how energy systems of the future are being shaped. On the DH generation side there is an increasing potential of integrating new low-grade heat sources and including heat generation from renewable energy sources as well as large scale heat pumps. For example, heat pumps 
can act as a balancing capacity when there is an over generation of electricity from intermittent renewable energy (Lund et al., 2014).

On the customer side of the DH system, the heat demands per building are expected to decrease as a result of the buildings becoming more energy efficient. Many new buildings are today designed as low-energy or near zero energy buildings. These buildings are usually equipped with space heating systems such as floor or wall heating, which require lower supply temperatures than those of radiator systems in conventional buildings (Lund et al., 2014).

In order to transition into a future sustainable energy system, both from the generation as well as the customer side, the fourth generation of district heating (4GDH) has been proposed, which is mainly characterized by lower operating temperatures of approximately $45-55^{\circ} \mathrm{C}$ supply and $20-30^{\circ} \mathrm{C}$ return on the primary side. However, in order to enable an implementation of the $4 \mathrm{GDH}$ it has to be done gradually, in conjunction with the existing 3GDH system's generating units, distribution networks and customer's heating systems. Despite an increasing share of buildings with lowtemperature space heating systems the temperature demands of the existing building stock will continue to remain high for many years to come (Lund et al., 2014). Therefore, in order to enable a transition to the next generation DH systems it is crucial to develop strategies on how to convert the heating systems of the existing building stock to operate on low-temperature district heating (LTDH). However, before such strategies can be completely developed and realized, profound knowledge and information about the operating parameters of the current system is crucial, where the radiator temperatures present is one important parameter.

\subsection{Previous Work}

In general, statistics of the temperatures on the primary side in the DH system is well documented since this information is something the DH companies keep records of for operating and billing purposes. Statistics of the temperatures on the secondary side, in the radiator systems, are on the other hand something that is more difficult to access.

The Swedish government issued in 2006 a directive to the National Board of Housing Building and Planning to conduct a study in which the technical status of the current building stock was to be surveyed, called the BETSI project. This was because the available information and statistics of the existing building stock was obsolete and incomplete. However, the survey, in which information about energy demands and building services was gathered, did not include any investigations on the temperature levels of the radiator systems (Boverket, 2010b).

\subsection{Purpose}

The main purpose of this master's thesis is to establish what the actual temperatures in radiator systems in existing buildings are through a survey. In order to correlate the findings of the survey to LTDH and 4GDH, factors affecting the temperature levels will be investigated as well as the potential of reducing the current temperature levels to those corresponding to the $4 \mathrm{GDH}$ will be evaluated. 


\section{$1.3 \quad$ Scope \& Objective}

The radiator systems in this survey are located in multi-family buildings throughout different areas in the Gothenburg district heating system, which is owned and operated by Göteborg Energi AB. The buildings are owned by the public housing company Bostads AB Poseidon which also operates and monitors the radiator systems. This is done through digital substations and a SCADA (Supervisory Control and Data Acquisition) system. Bostads $\mathrm{AB}$ Poseidon is one of the major customers in the Gothenburg district heating system with approximately 330 substations, 26600 apartments and 1.8 million $\mathrm{m}^{2}$ of heated area. Each substation serves from 20 up to a 300 apartments. In this survey, data from 109 radiator systems has been collected, which corresponds to approximately one third of all substations belonging to Bostads AB Poseidon. The reason behind the selection of these systems will be further explained in Chapter 3 of this report. Despite more data being available than that included in this study, measurements from a minimum of 100 substations was regarded as statistically sufficient. The temperature data consist of hourly average measurements and have been recorded by the digital substations. Manual measurements of temperatures from individual radiators have not been taken.

Only temperatures in radiator systems have been surveyed. Space heating systems with a different heat emitter type for domestic use, such as fin tube convectors or fan coils have not been included. Neither has any other space heating system, such as floor heating systems. Additionally, only temperatures required for the space heating demand have been included, which means that temperature requirements for domestic hot water generation have been disregarded. Also, when evaluating the potential of reducing the $\mathrm{DH}$ operating temperatures to those corresponding to $4 \mathrm{GDH}$, the required temperature differences ensuring sufficient driving forces between the primary and secondary sides of the DH system, have not been investigated in detail.

The objective with this survey is to provide statistics about the current temperatures in radiator systems in multi-family buildings as well as a comprehension about the factors affecting those temperatures. The intent with the study is to provide information to aid further research on the district heating technology development. This study can also provide a useful input for a future transition to lower operating temperatures for existing district heating systems and existing buildings, as well as in exploring the possibilities of implementing temperature reductions in the district heating system during parts of the year more promptly. 


\section{Theory}

This chapter provides some basic theory about the primary side of the district heating system as well as the secondary side where the radiator systems, also referred to as the space heating systems, are located. This chapter also serves as a background to this study.

\subsection{District Heating}

The third generation district heating system is the current and most common district heating technology in Northern Europe. In Sweden, district heating (DH) accounts for approximately $60 \%$ of the bought energy for heating purposes for the residential and service sectors (Frederiksen \& Werner, 2013). The customers connected to the DH system are mainly buildings which utilize the heat for space heating ( $\mathrm{SH}$ ) and generation of domestic hot water (DHW) (Lauenburg, 2016).

In multi-family buildings in Sweden, DH is the dominating heat source and covers $91 \%$ of the total energy bought for SH and DHW. For single family dwellings there is a larger variety of different types of heat sources present and DH accounts for barely $19 \%$ of the total energy used for SH and DHW (Energimyndighet, 2015).

The DH systems can be either indirectly or directly connected to its customers. In Sweden, all major DH systems have indirect connections. This means that there is hydraulic separation between the DH supply side and the customer's heating system on the secondary side. The most common customer heating systems comprise hydronic radiators. A direct connection is fairly common in the Danish DH systems where the water from the DH generating units is supplied directly in the customer's space heating system. Since no heat exchanger is used, the need for a temperature difference between primary and secondary sides to ensure sufficient driving forces, is eliminated. However, a potential leak in the DH system could be devastating (Frederiksen \& Werner, 2013).

\subsubsection{Substations}

The indirect connection to the district heating system implies that there is hydraulic separation between the primary side of the system and the customer, something which is achieved by a plate frame heat exchanger being part of a substation. In the substation the pressures and temperatures supplied on the primary side are lowered for safer use on the secondary side, where the building heating systems are connected. Compared to a direct DH system the main benefit with an indirect system is the reduced severity in the event of a radiator leakage (Frederiksen \& Werner, 2013). In the Gothenburg district heating system there are approximately 20000 substations. The majority of the substations are owned and controlled by the DH system owner; Göteborg Energi AB, but for a housing company the size of Bostads AB Poseidon, the ownership as well as control and monitoring of the substations belong to the housing company itself.

There is a vast variety of different types of connection configurations for the $\mathrm{SH}$ and DHW system's heat exchangers in the substation. The most common connection utilized in Swedish DH systems is the two-stage or parallel connection. By utilizing a two-stage connection the heat can be cascaded, which means that it is released in stages of lower temperatures. In this way the incoming cold water can be preheated with the lower temperatures of the DH primary water about to be returned, see Figure 1. 
Cascading can allow for the achievement of lower return temperatures (Frederiksen \& Werner, 2013).

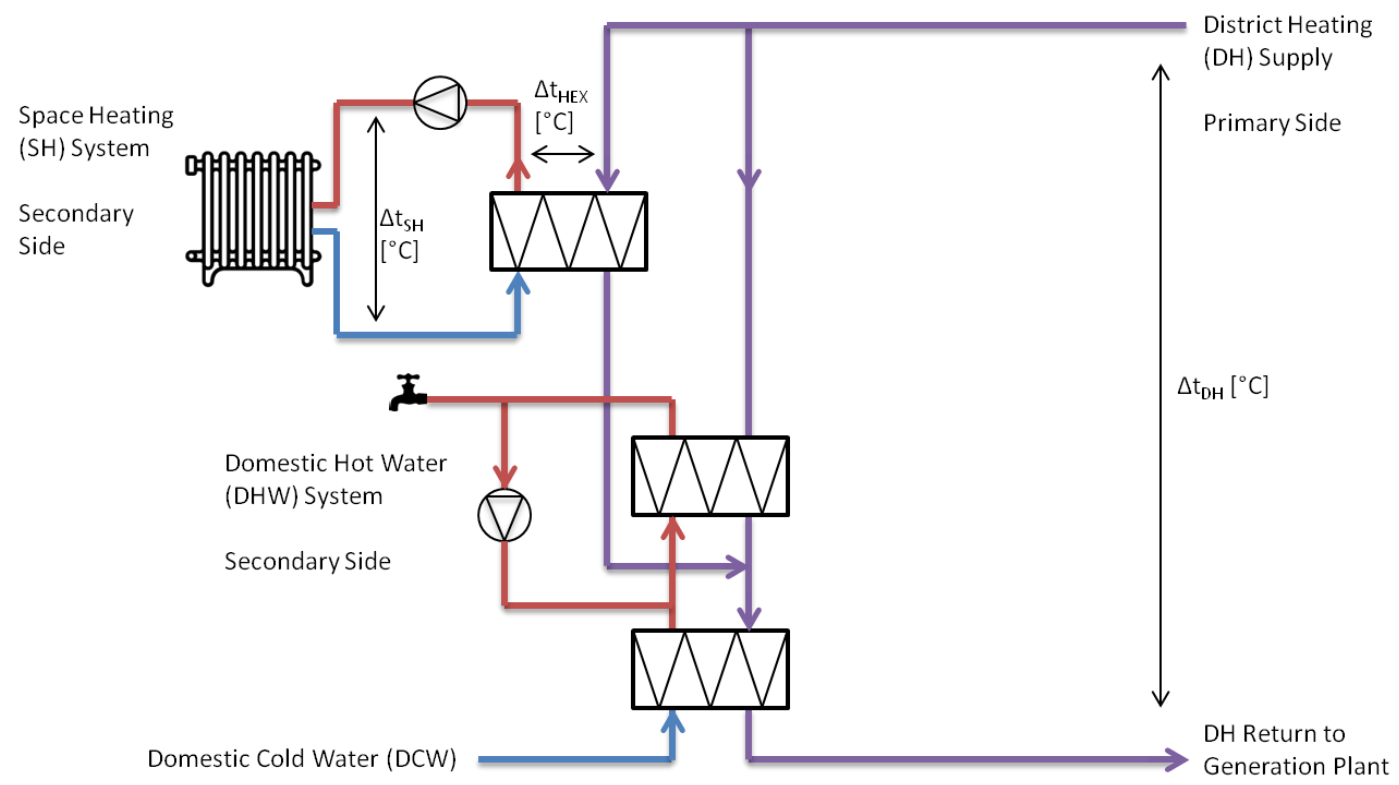

Figure 1: Schematic of a two-stage connection in a district heating $(D H)$ system substation. The DH primary supply side pipeline is split up to simultaneously provide heat via a heat exchanger to the building space heating (SH) system as well as the building domestic hot water (DHW) system, both located on the secondary side of the DH system. The DH primary supply pipe is reconnected to one pipe prior to the final heat exchanger which preheats the incoming domestic cold water $(D C W)$. After the DHW preheater the $D H$ pipeline is returned back to the $D H$ generating units. The three temperature differences of interest in the substation are the temperature difference on the primary side, labeled $\Delta t_{D H}$, the temperature difference in the SH system, $\Delta t_{S H}$, and the temperature difference across the heat exchanger between $\mathrm{DH}$ and $\mathrm{SH}$ systems, $\Delta t_{H E X}$.

The substations can communicate digitally with external units via the Internet and can therefore be set up to run automatically to enable remote control and monitoring from a central overseeing all substations. For optimal operation, assurance of adequate heat deliveries and troubleshooting in the event of malfunctioning, the SH system has to be monitored continuously. This is facilitated by the use of a Supervisory Control and Data Acquisition (SCADA) system in which the automated control can be supervised and interfered if necessary. Data acquisition from the substation can include hourly measurements of supply and return temperatures, pressures and water flow rates, and can be accessed through the SCADA system and utilized for system outcome analysis among others (Frederiksen \& Werner, 2013).

\subsubsection{Temperature Levels in the District Heating System}

The temperatures in the $\mathrm{DH}$ systems in Sweden have annual averages of $86^{\circ} \mathrm{C}$ supply and $47^{\circ} \mathrm{C}$ return (Gadd \& Werner, 2014), which depend on the requirements of the endusers. The DH supply temperature must be sufficient to meet the temperature demands of the SH systems and DHW generation. Simultaneously, the flow rates in the DH system must be kept at a reasonable low level in order to avoid high water velocities (Lauenburg, 2016).

The DH supply temperatures vary with the outdoor temperature. The heat generation units of Göteborg Energi $\mathrm{AB}$ operate according to benchmark values ranging from a low of $75^{\circ} \mathrm{C}$ for outdoor temperatures between $7-12^{\circ} \mathrm{C}$ and up to $110^{\circ} \mathrm{C}$ for outdoor temperatures of between $-13^{\circ} \mathrm{C}$ and $-20^{\circ} \mathrm{C}$, see Figure 2. For outdoor temperatures 
greater than $12^{\circ} \mathrm{C}$ the $\mathrm{DH}$ supply temperature is increased from $75^{\circ} \mathrm{C}$ up to $93^{\circ} \mathrm{C}$ in order to provide heat for absorption chillers for the district cooling system. These benchmark temperatures are set so that the $\mathrm{DH}$ customers can be guaranteed temperatures that are approximately $10^{\circ} \mathrm{C}$ less than those leaving the generation plant, although deviations to these values are regularly applied for different reasons. If the benchmark temperatures are supplied, a $10^{\circ} \mathrm{C}$ temperature drop from the generation units to the customer substation can be allowed for.

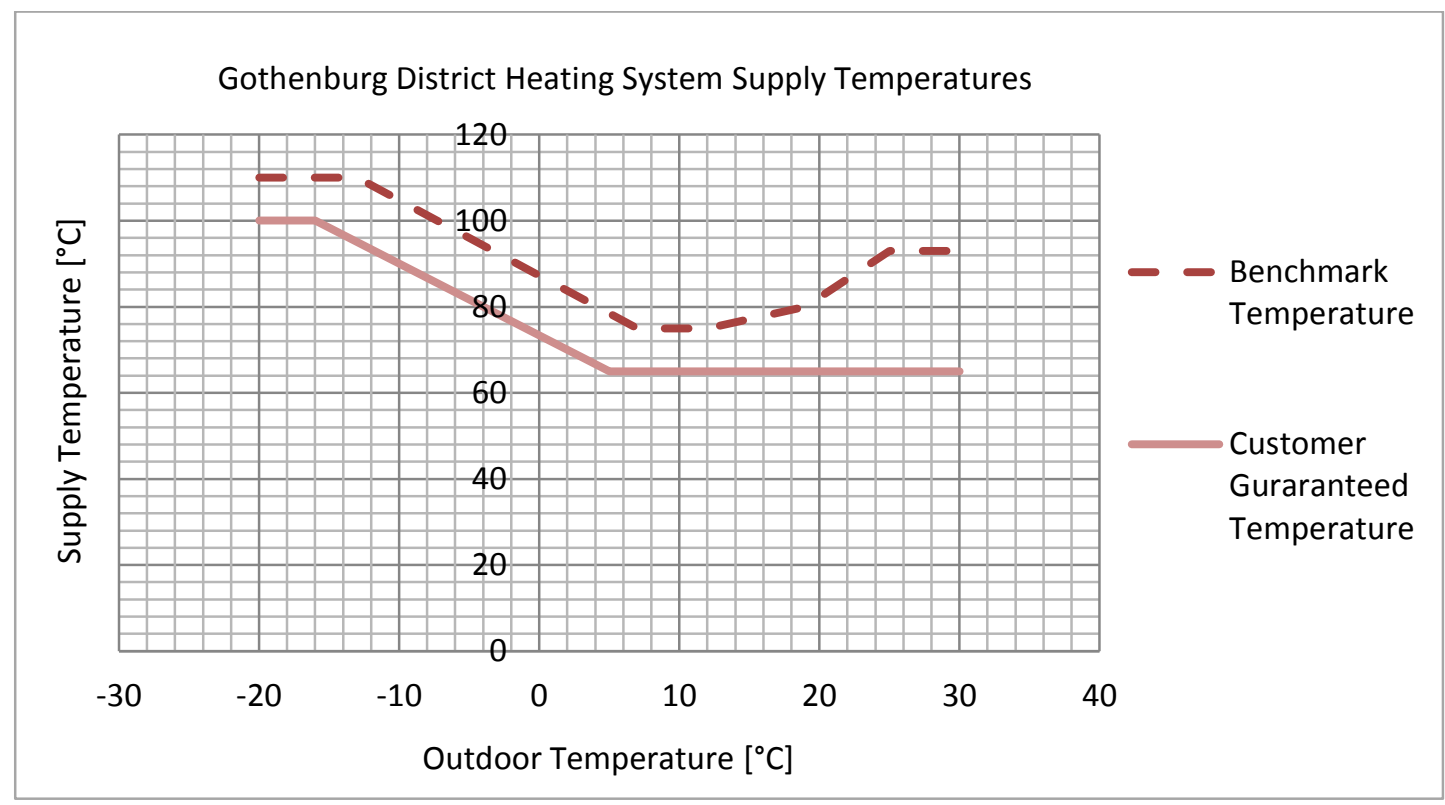

Figure 2: District heating benchmark supply operating temperatures and corresponding customer guaranteed supply temperatures as a function of the outdoor temperature for Gothenburg DH system. Courtesy of Göteborg Energi $A B$, reproduced with permission.

It is desirable to avoid unnecessarily high supply temperatures as well as the return temperatures should be reduced as much as possible. This is because low DH operating temperatures generate several benefits. These include reduced distribution heat losses, increased efficiency from combined heat and power generation units for the same heat demand, additional heat to recover in flue gas condensers as well as an increased lifetime of the distribution pipes. These benefits generate significant cost savings for the DH suppliers. Depending on the configuration of the heat supply plants of the DH system, and their response to a lowered return temperature, a cost reduction gradient for a specific DH system can be calculated where a typical value is $1.5 \mathrm{SEK} / \mathrm{MWh}^{\circ} \mathrm{C}$ (Frederiksen \& Werner, 2013). By minimizing the DH return temperature, possibilities of reducing the mass flow rate of the DH water and still transfer the same amount of heat are also enabled (Johansson, 2011). Göteborg Energi AB has in order to incentivize this based their DH billing on a return temperature fee. If the customer returns the DH water with a temperature above the average this results in a fee and if the return temperature is below the average a price reduction is granted.

Currently many substations and secondary systems in the district heating system operate with faults. This results in the necessity to provide supply temperatures that are significantly higher than the temperatures required by the end-users. By having a substantial margin between the DH supply temperatures and the required end-use temperatures, faults that occur in substations and the SH systems can be compensated for without compromising on the comfort of the end-users. This leads to unnecessarily high supply temperatures, and the notion that substations and secondary systems work 
correctly, when in fact there is important troubleshooting to be done in order to discontinue the production of excessive temperature levels and achieve primary energy savings. With improved techniques and methods for detecting and resolving the faults that occur in substations and secondary systems, the DH primary supply temperatures have the potential of being reduced considerably (Gadd \& Werner, 2015).

\subsubsection{Capacities in the District Heating System}

A DH system is dimensioned for a certain heat delivery capacity to ensure that the heat demands of the customers connected to the system are met. Usually a DH system is designed with some margin to allow for the addition of new customers. However, when more customers are added to an existing DH system, the capacity margin diminishes and may eventually result in heat delivery limitations for certain areas of the system. Depending on the limiting factor of the afflicted part of the DH system, the problem can either be solved by adding or reinforcing the distribution pipes or by adding local generating capacity, something that requires large investments. If no additional capacity is provided, an increased differential pressure in the system can be a temporary solution. Also, accepting short periods of reduced $\mathrm{DH}$ water flow could be another temporary solution. However, this leads to competition between the customers, with the buildings furthest away from the heat generation unit being the ones receiving insufficient heat deliveries (Johnsson, Rossing, \& Wallentun, 2009).

In substations where the temperature difference on the primary side, $\Delta \mathrm{t}_{\mathrm{DH}}$ in Figure 1, is decreased but the heat demand remains unchanged, the resulting effect will be a need for a greater primary water flow rate. If there are several substations in the same area with a decreasing $\Delta \mathrm{t}_{\mathrm{DH}}$, the increased flow rate demand will be aggregated and eventually affect the capacity margins of the DH system as a whole (Johnsson et al., 2009).

The Gothenburg DH system comprises generation units located in different areas of the distribution network. Parts of the DH system are suffering from low capacity margins, which Göteborg Energi AB today manages by elevating the supply temperatures when the outdoor temperatures require peak heat generation and distribution. If that is insufficient to meet the increased heat demand, local heat only boilers are started to supplement the heat deliveries. However, improvements in the customer's substations, such as increasing the temperature difference, $\Delta \mathrm{t}_{\mathrm{DH}}$, could facilitate the management of this situation significantly.

\subsubsection{Temperature Difference Across Heat Exchanger}

In order to evaluate the temperature levels on the secondary side of the DH system in relation to LTDH, the temperature difference required across the heat exchanger in indirect DH systems needs to be accounted for, see $\Delta \mathrm{t}_{\mathrm{HEX}}$, in Figure 1 . In order to avoid excessively large heat exchanging surfaces there is a minimum $\Delta t_{H E X}$ ensuring that there are sufficient driving forces for heat to be exchanged between the primary and the secondary sides of the DH system. The minimum $\Delta \mathrm{t}_{\mathrm{HEX}}$ is typically between $5-10 \mathrm{~K}$, where higher values are required if a smaller heat exchanger is of essence (Svensson, 2014). The temperatures on the primary side of the DH system needs to be high enough to account for the $\Delta \mathrm{t}_{\mathrm{HEX}}$, which means that the primary temperatures have to be greater than those encountered in the radiator systems on the secondary side. 


\subsection{Radiator Space Heating Systems}

Hydronic heating systems are utilized in $94 \%$ of the multi-family dwellings in Sweden and the most common heat emitters installed in these systems are radiators (Boverket, 2010a). However, radiators can be modified and designed in many different ways for enhanced heat output. Examples include radiators that have multiple panels as well as convectors added between the panels. Other possible heat emitters include the ventilation-radiator which is a radiator with an outside air intake through a wall channel on one side of the radiator. The outside air is heated by the radiator prior to entering the room. The ventilation-radiator can provide lower radiator surface temperatures than traditional radiators while meeting the required heat demand (Myhren \& Holmberg, 2009). In the buildings belonging to Bostads AB Poseidon the majority of the radiators are traditional panel radiators, but some ventilation-radiators are also installed in a few of the buildings.

The radiator systems in Bostads AB Poseidon's buildings serve between 20 and 300 apartments, with the majority of the systems serving less than 100 apartments. Depending on the apartment size and number of rooms, different amounts of radiators are installed in each apartment. On average, 4.5 radiators are installed per each 2-room apartment and 5.5 radiators in every 3-room apartment. Therefore, each radiator system substantially varies in size.

The radiator distribution system supplies heat by means of hot water through supply distribution pipelines to the radiators located in the apartments. The water is cooled in the radiator as it is giving up heat and then returned to the substation through the return pipelines. The distribution system can be arranged in many different ways where the most common installation is the 2-pipe system. In a 2-pipe system the supply and return pipelines are separated and smaller supply lines branch off from the main to serve each radiator, which are connected in parallel. The return lines from each radiator converge back to the main return pipeline which then reverts the water back to the substation, see Figure 3. Other distribution system configurations include the 1-pipe and 3-pipe systems, but are much more uncommon than the 2-pipe system. For the 1-pipe system the supply and return pipes are composed of the same pipeline to which the radiators are connected. For each radiator, the required flow is drawn off and the remainder directed along the main pipeline. The radiator return water becomes the supply water for the radiators located downstream. For a 3-pipe system the configuration is essentially the same as for 2-pipe systems, with the exception of reversing the return pipe in order to minimize the differential pressure across the radiators (Trüschel, 2002). The majority of the radiators in the buildings of Bostads AB Poseidon are connected in parallel with a 2-pipe configuration as shown in Figure 3.

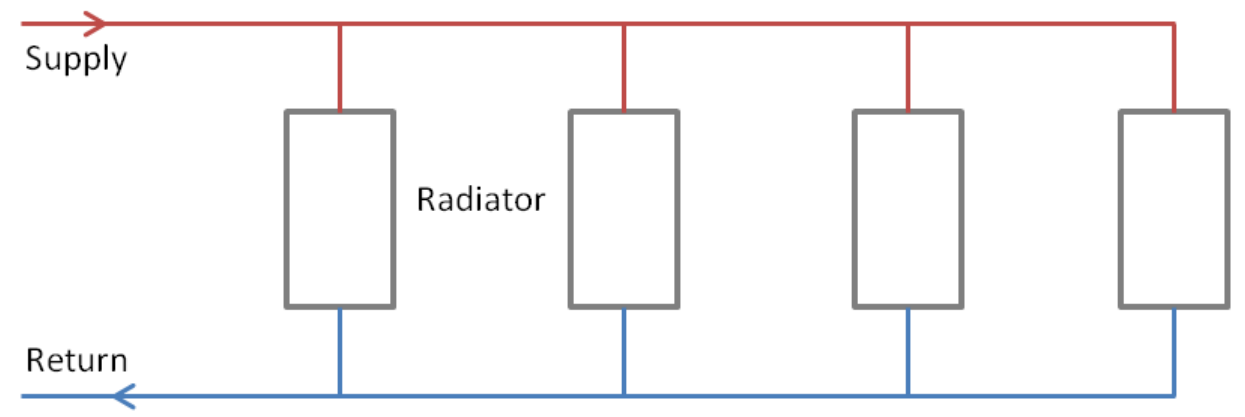

Figure 3: Arrangement of a radiator system configuration showing a 2-pipe system with radiators connected in parallel. This is the most common configuration of radiator systems in general, as well as the systems part of this study. 


\subsubsection{Radiator Design}

The design process of selecting the heat emitting component in the heating system involves determining the size of the heat transferring area in order to ensure that the heating need will be fulfilled (Trüschel, 2002). For heat transfer between two media it is important to relate the total heat transfer rate to the inlet and outlet fluid temperatures, the overall heat transfer coefficient and the total surface area for heat transfer. For a counter flow heat exchanger, the following Equation is utilized (Incropera et al., 2005):

$$
\dot{\mathrm{Q}}=\mathrm{U} \cdot \mathrm{A} \cdot \Delta \mathrm{t}_{\mathrm{ln}}
$$

Where

$\dot{\mathrm{Q}}=$ Thermal power transferred [W]

$\mathrm{U}=$ Coefficient of thermal transmittance $\left[\mathrm{W} / \mathrm{m}^{2} \mathrm{~K}\right]$

$\mathrm{A}=$ Heat transfer area $\left[\mathrm{m}^{2}\right]$

$\Delta \mathrm{t}_{\mathrm{ln}}=$ Logarithmic mean temperature difference between hot and cold flows [K]

For the case of a radiator the heat transfer will take place between the water inside the radiator, the surrounding air and the walls of the room where the radiator is located. This means that the exchange of heat will occur as a combination of convection and radiation and the heat transfer will be of non-linear characteristic. The coefficient of thermal transmittance for radiation is highly dependent on the temperatures between the surface temperature of the radiator, the air and the walls within the room (Abel et al., 1995). Hence, Equation (1) needs to be modified to correctly represent the thermal power released, and for a panel radiator the following approximated expression has been developed (Trüschel, 2002):

$$
\dot{\mathrm{Q}}_{\mathrm{rad}}=\mathrm{K}_{\mathrm{rad}} \cdot \Delta \mathrm{t}_{\mathrm{ln}}{ }^{\mathrm{n}}
$$

Where

$\dot{\mathrm{Q}}_{\mathrm{rad}}=$ Thermal power output from radiator $[\mathrm{W}]$

$\mathrm{K}_{\mathrm{rad}}=$ Radiator constant $\left[\mathrm{W} / \mathrm{K}^{\mathrm{n}}\right]$

$\mathrm{n}=$ Radiator exponent [-]

For radiators, the logarithmic mean temperature difference is the mean temperature difference between the inlet and outlet temperatures of the water and the room temperature of the air, and can be expressed as follows (Trüschel, 2002):

$$
\Delta t_{\ln }=\frac{t_{\text {rad }, \mathrm{s}}-t_{\text {rad, } \mathrm{r}}}{\ln \left(\frac{\mathrm{t}_{\text {rad }, \mathrm{s}}-\mathrm{t}_{\text {room }}}{\mathrm{t}_{\mathrm{rad}, \mathrm{r}}-\mathrm{t}_{\mathrm{room}}}\right)}
$$

Where

$\mathrm{t}_{\mathrm{rad}, \mathrm{s}}=$ Radiator supply temperature $\left[{ }^{\circ} \mathrm{C}\right]$

$\mathrm{t}_{\mathrm{rad}, \mathrm{r}}=$ Radiator return temperature $\left[{ }^{\circ} \mathrm{C}\right]$

$\mathrm{t}_{\text {room }}=$ Room temperature $\left[{ }^{\circ} \mathrm{C}\right]$

Both the radiator constant, $\mathrm{K}_{\mathrm{rad}}$, and the radiator exponent, $\mathrm{n}$, depend on the size and design of the radiator and are often utilized in different ways as design parameters by 
radiator manufacturers to describe properties of different radiators. The radiator exponent, n, is introduced in Equation (2) because of the non-linearity of the heat transfer and its value has been experimentally determined. For radiators the exponent is approximately 1.33 whereas for convectors it is around 1.25 (Abel et al., 1995).

\subsubsection{Radiator Sizes}

In order to investigate how the radiator temperatures vary with the radiator heat transfer area (also referred to as the radiator size), the radiator constant, $\mathrm{K}_{\mathrm{rad}}$, was calculated for each system as a whole. $K_{\text {rad }}$ can be compared to the product $U \cdot A$ in Equation (1). Since $\mathrm{U}$ is highly temperature dependent it can be simplified as follows in order to be utilized in Equation (2):

$$
\mathrm{U}=\mathrm{f}(\Delta \mathrm{t}) \approx \mathrm{K} \cdot \Delta \mathrm{t}^{\beta}
$$

By inserting Equation (4) into Equation (1) from Section 2.2.1 it then becomes similar to Equation (2):

$$
\dot{\mathrm{Q}}=\mathrm{K} \cdot \Delta \mathrm{t}^{\beta} \cdot \mathrm{A} \cdot \Delta \mathrm{t}=\mathrm{K} \cdot \mathrm{A} \cdot \Delta \mathrm{t}^{\beta+1}
$$

Where

$\mathrm{K} \cdot \mathrm{A}=\mathrm{K}_{\mathrm{rad}}$ and

$\beta+1=\mathrm{n}$

$\mathrm{K}_{\mathrm{rad}}$ will in this way be correlated to the heat transfer area of the radiator. Since the amount of radiators in each system part of this study vary from system to system, an overall radiator constant per system can be calculated and then normalized per square meter of heated area of that system according to the following expression:

$$
\mathrm{K}_{\text {rad,n }}=\frac{\mathrm{K}_{\text {rad,system }}}{\mathrm{A}_{\text {system }}}\left[\frac{\mathrm{W}}{\mathrm{K}^{\mathrm{n}} \mathrm{m}^{2}}\right]
$$

Where

$\mathrm{K}_{\text {rad,system }}=$ Overall radiator constant per radiator system $\left[\mathrm{W} / \mathrm{K}^{\mathrm{n}}\right]$

$\mathrm{A}_{\text {system }}=$ Heated area per radiator system $\left[\mathrm{m}^{2}\right]$

The normalized radiator constant per square meter of heated area, $\mathrm{K}_{\mathrm{rad}, \mathrm{n}}$, will then give an indication of the radiator sizes in the radiator systems surveyed.

Equation (2) was utilized to calculate $\mathrm{K}_{\text {rad,system, where the logarithmic mean }}$ temperature difference, $\Delta \mathrm{t}_{\mathrm{ln}}$, of the radiator systems was calculated using Equation (3). The hourly temperature measurements for the radiator supply and return temperatures were applied for $t_{\text {rad,s }}$ and $t_{\text {rad,r. }}$. The value for $t_{\text {room }}$ was assumed to be $21^{\circ} \mathrm{C}$ for all outdoor temperatures, except for when the radiator supply or return temperatures were lower than that. For such instances the room temperature was assumed to be slightly less than the radiator return temperature. This was done so that heat transfer could still be accounted for, despite low supply and return radiator water temperatures, instead of removing these temperature measurements altogether. The set points for the radiator circulation pump stop were utilized as the building balance temperature (which is further explained in Section 2.2.5), above which no heating is needed. Therefore, all supply and return temperature values above that set point were omitted. Also, for all 
hours when the outdoor temperature was less than the set point for pump stop, but yet the return temperature was greater than the supply temperature, it was assumed that the circulation pump was stopped and no heat was supplied. The value for the radiator constant, $\mathrm{n}$, was set to be 1.3 for the calculation of $\mathrm{K}_{\mathrm{rad}}$.

Data for the specific energy demand per square meter was obtained for each radiator system. However, this data included the heat used for DHW generation. In order to remove the amount of heat utilized for DHW the heat utilization of the month of July, where no space heating was assumed to be provided, was chosen to represent the DHW heat consumption and applied for the rest of the year. The DHW share of the total building specific heat usage resulted in the majority of the buildings having a DHW share of approximately $30 \%$, with the building with lowest DHW share being $20 \%$ and the highest $63 \%$. However, this method was not able to account for the varying temperatures of the incoming DCW, which depend the outdoor temperature, and therefore requires different amounts of heat depending on the time of the year.

\subsubsection{Radiator Design Temperatures}

The design temperatures of the radiator systems vary between countries, but have also been different throughout the years. Common for most SH systems is the aspiration of utilizing lower temperatures since they determine the operating temperatures of the $\mathrm{DH}$ system. In Sweden, high design temperatures of $90 / 70^{\circ} \mathrm{C}$ and $80 / 60^{\circ} \mathrm{C}$ supply and return have traditionally been used. These temperature levels were an outcome due to lack of incentives for utilizing lower temperatures in hydronic heating systems supplied by boilers. These temperature levels also lead to the possibility of having small radiators (Lauenburg, 2016). In 1982 there was a revised Swedish building code restricting the radiator design supply temperatures to no more than $55^{\circ} \mathrm{C}$, and for some cases $60^{\circ} \mathrm{C}$ (Frederiksen \& Werner, 2013). This has led to radiator systems today usually being designed for lower supply and return temperatures such as $60 / 45^{\circ} \mathrm{C}, 60 / 40^{\circ} \mathrm{C}$ and $55 / 45^{\circ} \mathrm{C}$ (Wollerstrand et al., 2007). The radiator systems present in existing buildings can for that reason be categorized into low or high temperature systems (Trüschel, 2002).

The maximum radiator heat output as well as temperature program need to be based on the difference between the indoor temperature and the outdoor temperature on a very cold day. The required power to meet that heat demand represents the design power of the radiator. The temperature for which the design power of the radiator is selected is called the design outdoor temperature (DOT). This temperature varies depending on the climate of the particular location where the building is to be situated (Frederiksen \& Werner, 1993). For Gothenburg a common DOT for the design of radiators is $-16^{\circ} \mathrm{C}$, which will also be utilized in this study.

\section{Over dimensioning of Radiator Systems}

Another factor affecting the temperatures in the radiator systems is the degree of over dimensioning of the radiators, which is common in the existing building stock. The amount of over dimensioning is usually at least $10 \%$, but sometimes even $100 \%$ or more. It depends on how much the building heat demand has been over estimated, but also on the fact that larger components than necessary usually are selected in order to ensure a safety margin. Over dimensioning can also arise as a result of implementing building energy savings measures, such as adding building envelope insulation, replacing windows and installing heat recovery on the ventilation system. There are several possibilities of compensating for over dimensioned radiator surfaces. For 
example, the supply temperature curve can be shifted downwards, or the supply temperature can be maintained and the water flow rate can be reduced (Wollerstrand et al., 2007).

It is not only the size of the radiator that could generate implications if overdimensioned. Even if a correct radiator size is selected it is of outmost importance to select the right sizes of other system components as well, for instance control valves. The control valves have a relatively low flow transmission and if it is too large an excessive amount of water is passed without being cooled off (Nilsson, 2007).

\section{Optimization of Radiator Temperatures}

The cooling of the water in the DH system, also referred to as the temperature difference between the primary supply and return sides, see $\Delta \mathrm{t}_{\mathrm{DH}}$ in Figure 1, will be the greatest at DOT. However, at partial heat load the cooling may not be the most optimal. For every combination of substation and radiator system within the DH system, there is for different heat loads and primary DH supply temperatures, an optimal flow rate in the radiator system generating the lowest possible return temperature on the primary side. The cooling of the DH water is determined by the cooling in the radiator systems $\left(\Delta \mathrm{t}_{\mathrm{SH}}\right.$ in Figure 1). If the radiator systems fail to provide a sufficient $\Delta \mathrm{t}_{\mathrm{SH}}$ this will be transferred to the primary side of the DH system and excessively large DH water temperatures will be sent back to the generating units (Wollerstrand et al., 2007). There are however other mechanisms affecting the return temperatures of the DH system, and one important aspect is the short circuits in the system, which may be both intentional and unintentional. In a short circuit the DH supply water is bypassed any heattransferring surfaces, leading to the return water having similar temperatures to that of the supply water (Lauenburg, 2016).

At partial heat load the radiator system has an overcapacity, which can be compared to an over dimensioned radiator system, as described in the previous section. The installed radiator surfaces (indicated by the radiator constant, $K_{\mathrm{rad}}$, as described in Section 2.2.1) will therefore be larger than needed for all other heat loads than those required at DOT. This would also be the same for an over dimensioned radiator system, but potentially for outdoor temperatures lower than DOT as well, depending on the degree of over dimensioning. The most optimal cooling in a specific radiator system at partial load, or for over dimensioned systems, can therefore be achieved if the radiator water flow rates are adjusted for at partial heat load. For radiators with larger heat transfer surfaces there is a greater potential of optimizing the supply and return temperatures by adjustment of the flow rate. This is because a large heat transfer surface can ensure that the required heat is delivered with a reduced flow rate, as opposed to radiators with smaller heat transfer surfaces (Wollerstrand et al., 2007).

\subsubsection{Hydronic Balancing}

Essentially, regardless of what supply and return temperatures the radiator has been designed for it is the selected hydronic balancing method that determines what the operating temperatures will become once the system is operating. The radiator water flow rate does not directly affect the heat released from the radiator since the heat transfer resistance between the water and the inner radiator surface is significantly lower than the heat transfer resistance between the outer radiator surface and the surrounding air. The water flow rate is however an important parameter on the water residence time within the radiator, hence influencing the temperature difference 
between the supply and return water, and also the mean temperature of the radiator surface (Wollerstrand et al., 2007).

Balancing of a hydronic radiator system is done by adjusting the balancing valves located on the radiator branches and/or the risers, in order to achieve the desired flow rate which will then generate a certain differential pressure across the system. The balancing methods can be categorized into the low and the high flow method. Low flow balancing utilizes a low water flow rate and reduces the pressure drop between the branch valves, resulting in a pressure drop being almost equal across all valves. The available differential pressure in the system will therefore be low. For the high flow method the water flow rate is high and the pressure drop in the radiator system greater than for the low flow, as is the interaction between the valves on the radiator branches (Trüschel, 2002).

For a radiator system balanced with a low water flow rate the temperature difference between radiator inlet and outlet will increase compared to a high flow rate. This is because it will take longer for the water with a low flow rate to pass through the radiator than it does for water with a higher flow rate. However, both the low and high flow method can utilize either low or high radiator supply temperatures. The difference will arise from the return temperature achieved from the two different balancing methods. For the low flow case, supply and return temperatures of $80 / 40^{\circ} \mathrm{C}$ and $70 / 30^{\circ} \mathrm{C}$ are common. For the high flow case, system temperatures of $80 / 60^{\circ} \mathrm{C}, 60 / 40^{\circ} \mathrm{C}$ or $55 / 45^{\circ} \mathrm{C}$ supply and return are common (Trüschel, 2002).

As stated above, the balancing methods can be categorized into the low or the high flow method. However, in practice, which is also the case for the radiator systems surveyed, a combination of the two is often utilized. The method Bostads AB Poseidon employs for the balancing of most of the radiator systems in their buildings is something in between the low and high flow methods. The flow rate is reduced in order to enhance a large temperature difference $\left(\Delta \mathrm{t}_{\mathrm{SH}}\right.$, in Figure 1$)$ across the radiator system and adjusted so that the supply temperature is set to $70^{\circ} \mathrm{C}$ for an outdoor temperature of $-20^{\circ} \mathrm{C}$. The corresponding return temperature then becomes $35-40^{\circ} \mathrm{C}$. This type of balancing typically yields supply temperatures of around $50^{\circ} \mathrm{C}$ at $0^{\circ} \mathrm{C}$ outdoor temperatures. The system is balanced by adjustment of the balancing valves on the radiator branches, and not the riser valves. Even though this process is the most common one for Bostads AB Poseidon when balancing their existing radiator systems as well as new ones, they utilize other methods as well. For example, if a radiator system in one of Poseidon's buildings has supply temperature of $45^{\circ} \mathrm{C}$ for an outdoor temperature of $0^{\circ} \mathrm{C}$, some other method has most likely been used. Therefore, an important parameter determining the temperature levels in the radiators system is the balancing method.

\subsubsection{Radiator Control and Monitoring}

When designing a radiator system, the supply temperature needed at DOT to ensure a sufficient indoor room temperature is achieved, is determined. Based on this, a radiator supply temperature control curve is set up so that the radiator supply temperatures for other outdoor temperatures also achieves the required room temperature. This temperature curve is based on the water flow in the radiators being constant. A constant radiator water flow generates a linear relationship between the radiator heat output and the temperature difference between the supply temperature and the room temperature. The resulting relationship between radiator supply and return temperatures will 
therefore give rise to an explicit expression developed by Kärkkäinen (Kärkkäinen, 2010). The findings of this survey will in Chapter 4 be compared to the temperatures obtained from this expression.

A supply temperature control curve, as mentioned above, is utilized in the radiator systems in Bostads AB Poseidon's radiator systems as well. For their systems the control curve is based on a piecewise linear relationship for every five or ten degree increment of the outdoor temperature. The outdoor temperature control interval ranges from -20 to $20^{\circ} \mathrm{C}$. The supply temperature is then adjusted for the different outdoor temperatures by controlling the flow limiting valve on the DH primary side of the heat exchanger. Many of the radiator systems have their own specific control curve with set points that have been determined from a temperature optimization. This optimization is done by checking the indoor temperatures for different outdoor temperatures. If the indoor temperatures have been excessive or insufficient the control curve set points are adjusted accordingly. For the systems where no temperature optimization has been performed the set points originate from the initial theoretical or design control curve set up during the installation, sometimes with slight changes or adjustments applied.

For the majority of Bostads AB Poseidon's radiator systems the supply temperatures are also controlled by monitoring the temperature of the ventilation exhaust air. If the average value recorded by the exhaust air temperature sensors is larger than a fixed limit value, the radiator supply temperature is lowered to supply less heat. This function is set to only reduce the supply temperatures of the radiator supply water, and not to increase them.

In case the heat demand in the building cannot be met, or if the supply temperatures are higher than needed, they can be shifted from the control curve set points in order to achieve an altered heat supply. This can be done manually by adding or subtracting degrees to the control curve set points for shorter periods of time or more permanently. If the supply temperature curve is shifted in either direction and not adjusted back it can be due to the human factor. If it is shifted down, meaning that the supply temperatures are reduced, and no need to shift the curve back up arises, this can indicate that the radiator system is over dimensioned, perhaps as a result of a renovation with implementation of energy savings measures, as stated previously.

The radiator system circulation pumps are set to automatically start and stop when the outdoor temperature reaches a predetermined set point, called the building balance temperature. The balance temperature corresponds to the outdoor temperature when the building internal heat gains, from for example electrical appliances and humans, are equal to the building heat losses. When the outdoor temperature is less than the building balance temperature there is a heating need. The balance temperature is typically between $15^{\circ} \mathrm{C}$ and $17^{\circ} \mathrm{C}$ but varies for different buildings. It depends on the heat transfer coefficient of the building envelope, but also on the internal heat generation rate and the building heat gain from solar radiation (Frederiksen \& Werner, 1993). The radiator system circulation pumps are arranged with different control strategies depending on the thermal inertia of the building, but they typically start with some time lag and turn off instantly when the balance temperature is reached.

Radiator thermostats is a control measure utilized to improve the indoor climate more locally than what can be done through the substation. The thermostats are mounted on or close to each radiator in the system and by measuring the surrounding air temperature the flow rate can be limited through the particular radiator if the temperature exceeds the set point. During normal operation of an ideally controlled radiator system the 
thermostatic valves should not have to be activated. It is only in case of additional external heat, such as solar radiation on a winter day, that the thermostatic valve operation should be triggered (Gustafsson \& Sandin, 2016). Radiators installed in Swedish multi-family buildings are virtually always equipped with thermostatic valves (Boverket, 2010a). This is also the case for the radiators located in Bostads AB Poseidon's buildings. 


\section{Survey Method}

A descriptive method in the form of a survey was chosen for this study in order to describe the present situation. Temperature data was collected for each radiator system part of the survey and it was analyzed by means of temperature plots. This was done in order to investigate the different radiator systems' behavior and to remove erroneous data measurements. Furthermore, in order to analyze the temperatures present, different factors potentially affecting them were investigated. This chapter explains how the survey was conducted and how the data was analyzed.

\subsection{Data Collection}

The data obtained for this survey consisted of hourly average temperature measurements for one year, from February $1^{\text {st }} 2015$ until January $31^{\text {st }} 2016$. The data included supply and return temperatures on the DH system side as well as radiator supply and return temperatures with corresponding outdoor temperatures. The data was downloaded directly from Bostads AB Poseidon's online SCADA system. In addition to temperature data, set point values for the supply temperature control curve, outdoor temperature for the radiator system circulation pump stop, building specific heat demand, heated area and building construction year were also obtained. In Figure 4 the configuration of the substation, typical for all radiator systems surveyed, is displayed along with the locations of the temperature sensors where the temperatures were recorded.

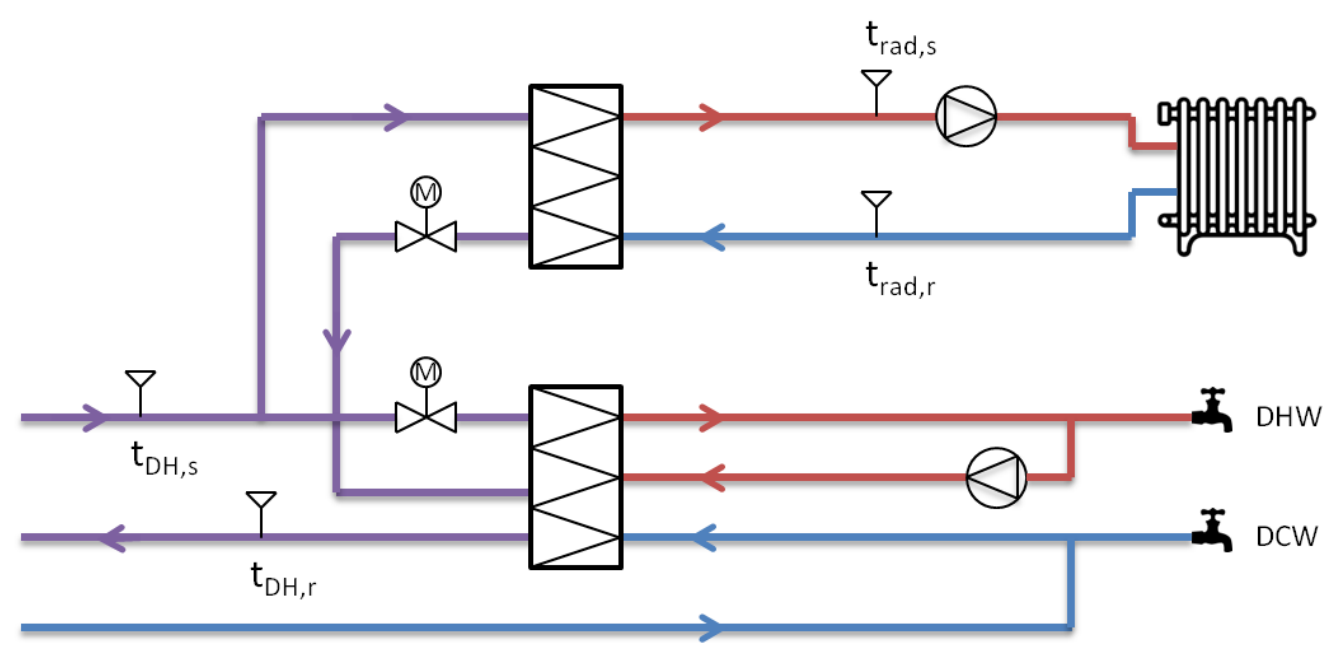

Figure 4: Schematic of substation configuration, typical for the radiator systems surveyed. The schematic also shows the locations of the temperature sensors where the obtained temperature data was recorded, for both primary and secondary sides.

\subsubsection{Categorization of Geographical Areas}

Bostads AB Poseidon owns buildings in many different parts of the city of Gothenburg. The buildings are divided into different districts based on their geographical locations. For this survey, buildings located in a few of these districts were selected for which data was obtained, see Figure 5. The following three criteria were used in order to select the areas from which the data was obtained: 
1. Location in Gothenburg DH system. The DH distribution system has different capacities throughout the different districts and different radiator temperatures could for that reason be present.

2. Amount of buildings with similar characteristics and construction year. To be able to compare the temperature data between different radiator systems it was desirable to obtain data from buildings with similar characteristics and approximately the same construction year.

3. Residential buildings and data available for one year. Some of the buildings owned by Bostads AB Poseidon are premises, garages or not representative of a typical residential building. In some of the districts maintenance or upgrades of the substations had resulted in data not being available for one year.

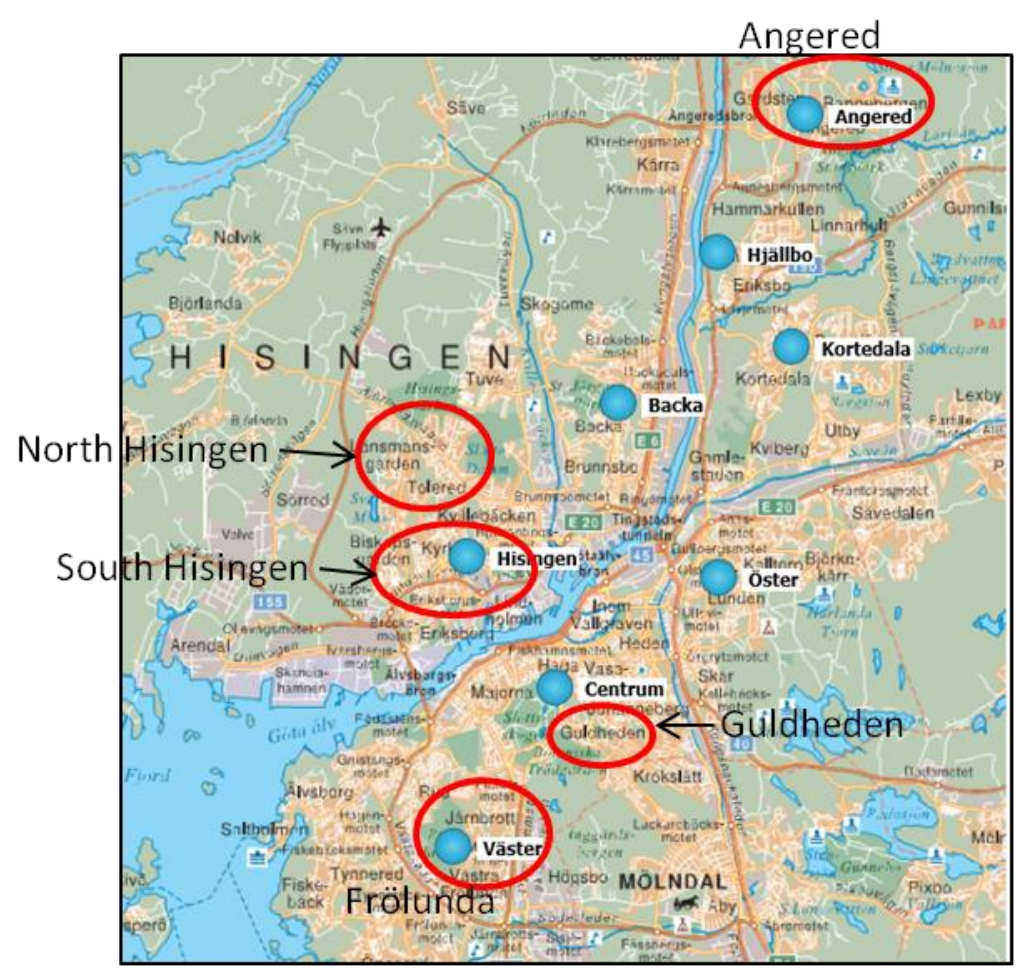

Figure 5: Map of Gothenburg with respective district part of the survey.

\subsubsection{Calculation of Supply and Return Temperatures at DOT}

Despite January of 2016 being a cold month, with periods of outdoor temperatures corresponding to that of the design outdoor temperature (DOT) for Gothenburg, few building outdoor temperature sensors had measurements for $\mathrm{T}_{\text {out }}=-16^{\circ} \mathrm{C}$. Therefore, the radiator supply and return temperatures at DOT were calculated based upon the available measurements. This calculation was done by forecasting the value based upon the available measured data for the outdoor temperatures recorded during the year, where the forecast interval was chosen so that the deviation of the calculated supply temperature from the control curve set point value was minimized.

The forecast equation is based on linear regression of the data points:

$$
\mathrm{a}=\overline{\mathrm{y}}-\mathrm{b} \overline{\mathrm{x}}
$$

Where the constant $b$ is obtained from the following Equation: 


$$
\mathrm{b}=\frac{\sum(\mathrm{x}-\overline{\mathrm{x}})(\mathrm{y}-\overline{\mathrm{y}})}{\sum(\mathrm{x}-\overline{\mathrm{x}})^{2}}
$$

Where

$\overline{\mathrm{x}}$ and $\overline{\mathrm{y}}=$ sample means

\subsection{Potential Factors Affecting the Temperature Levels}

In addition to establishing what the actual radiator temperatures are, some potential factors affecting the temperatures were investigated. This was done in order to correlate the findings of the survey to the temperatures of the future fourth generation district heating, and to evaluate the potential of a temperature reduction corresponding to these future temperature levels.

The data for each radiator system was analyzed by creating a temperature plot and examining the system's behavior by means of the data. This was done together with the operating engineers of Bostads AB Poseidon. Based on information from Chapter 2, the following information about the radiator systems was gathered and discussed to the extent possible:

- What balancing method that was employed for the systems and the year it was performed.

- If a certain feature to the space heating system was added. For example, heat pump integration in the radiator system or if a different type than regular panel radiators were installed.

- If the building had been renovated; year it was done and what measures that were implemented.

After scrutinizing the collected information and data about the radiator systems the following factors potentially affecting the temperature levels were selected for further investigation:

- Radiator sizes

- Building construction year

- Building specific space heating demand

- Hydronic balancing of the radiator systems 


\section{$4 \quad$ Results}

In the following chapter the results based on the data obtained from the survey and the corresponding analysis of the temperatures are presented. In the first section temperature plots of typical radiator systems used to analyze the temperature data are presented. In the remaining sections results from the survey as well as the factors potentially affecting the temperature levels are presented.

\subsection{Results from Data Analysis of Collected Data}

The radiator temperature data was analyzed graphically by means of temperature plots where the supply and return temperatures were plotted against the outdoor temperature. This method was utilized in order to verify the system condition and operation as well as to obtain information about the system behavior for different outdoor temperatures in relation to the control curve set points. The temperature plots looked different for different radiator systems and the following four figures show examples of a few types encountered. The temperature plot in Figure 6 indicates a regular system operation.

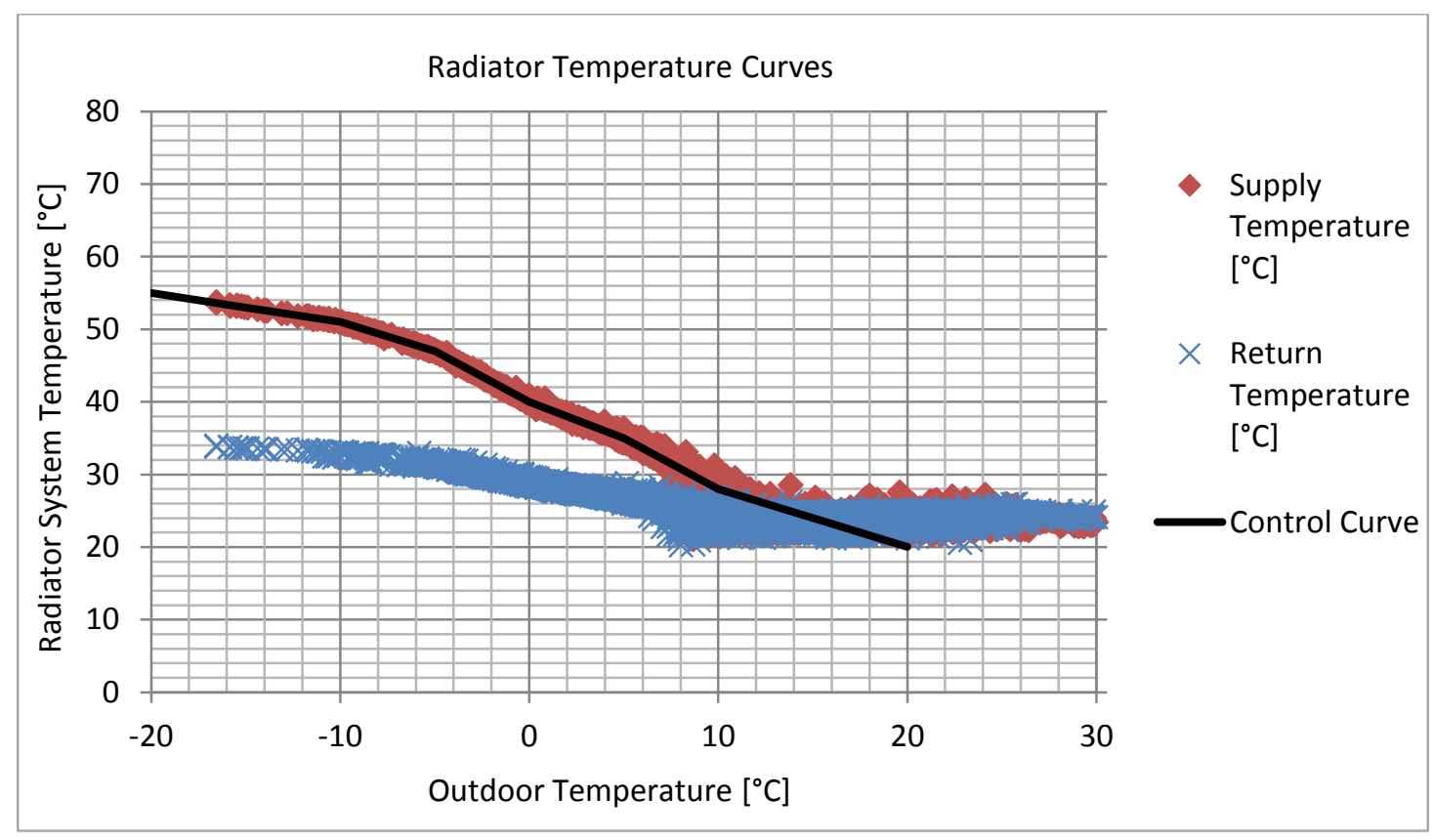

Figure 6: Temperature curve plot of radiator system for graphical analysis exhibiting operation of a regular system. The outdoor temperature is plotted as a function of the radiator supply and return temperatures, also showing the supply temperature set points of the radiator system control curve for the different outdoor temperatures.

The red diamond shapes represent the supply curve and the blue crosses the return temperatures. The black solid line is the supply temperature control curve. As can be seen, the actual supply temperatures coincide with the set points of the control curve. Instead of a completely linear relationship between the set points of the supply temperatures and the outdoor temperature, a piecewise linear relationship can be identified. For $\mathrm{T}_{\text {out }}=14-16^{\circ} \mathrm{C}$ the supply and return temperatures become stable and it can for that reason be assumed that the heating need of the building is met, and that the building's balance temperature corresponds to those outdoor temperatures.

As described in section 2.2.4 the supply temperatures can be shifted in either direction from the control curve set points in order to meet an altered supply temperature need. 
Figure 7 displays an example of supply temperatures that have been reduced, indicating that there is a lower heating need present than the one initially set to be provided.

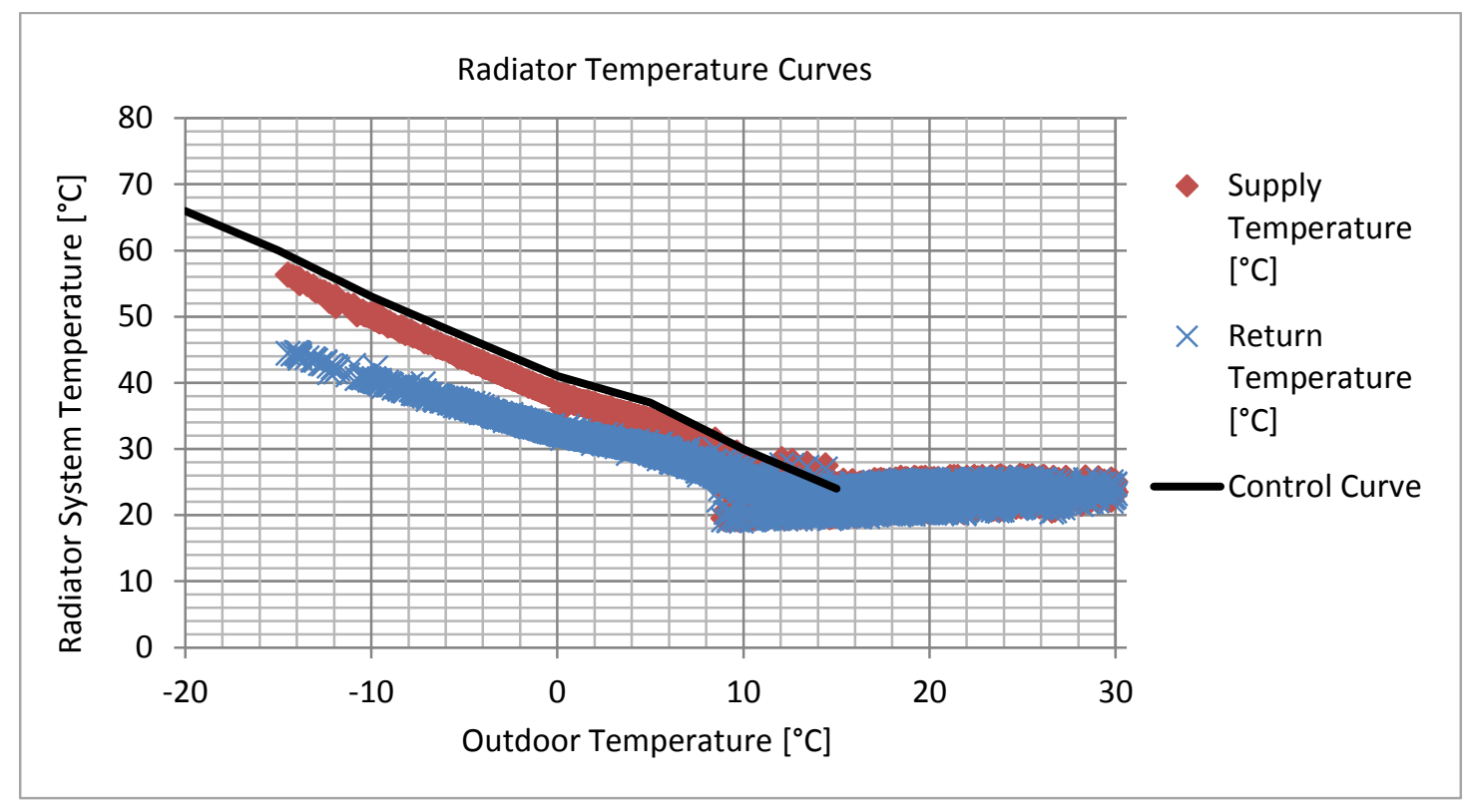

Figure 7: Temperature curve plot of a radiator system showing a supply temperature control curve shift, indicating a lower building heating need present than the one initially set to be provided.

The temperature plots were also utilized to identify erroneous data measurements. For instance; some temperature sensors on the radiator system side were most likely located close to the heat exchanger separating the radiator system from the DH system, hence recording unexpectedly high radiator supply temperatures for outdoor temperatures from approximately $10^{\circ} \mathrm{C}$ and up, see Figure 8 . This could be due to the fact that the circulation pump on the radiator side was turned off, therefore causing a stagnant water flow which notably elevates the supply temperatures. Such data measurements were for that reason removed prior to carrying out the calculations.

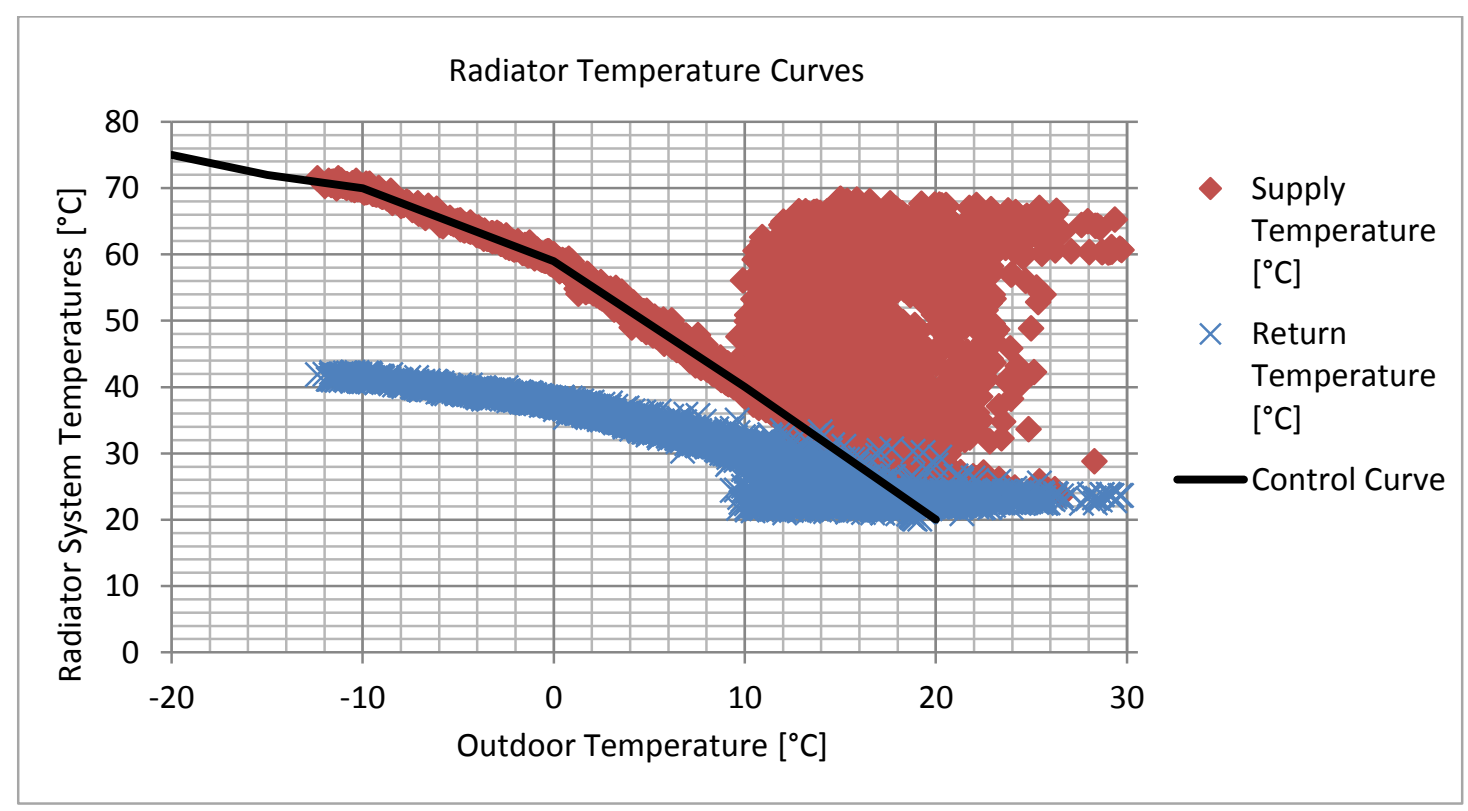

Figure 8: Temperature curve plot of a radiator system with supply temperature measurements indicating circulation pump stop, as well as the temperature sensor on the radiator supply side most likely is located close to the heat exchanger between the DH and SH sides, hence resulting in unexpectedly high radiator supply temperatures for $T_{\text {out }} \geq 10^{\circ} \mathrm{C}$. 
Some of the radiator systems revealed some other peculiar temperature measurements from inspection of their temperature plots. As can be seen in Figure 9, for $\mathrm{T}_{\text {out }}=0-2^{\circ} \mathrm{C}$ and $5-7^{\circ} \mathrm{C}$ both supply and return temperatures have decreased to almost $15^{\circ} \mathrm{C}$ during some hours. This could also be due to circulation pump stop, since both supply and return temperatures are approximately the same. However, since the outdoor temperature is less than the building balance temperature a potential pump stop could be unintentional because of malfunction or intentionally for maintenance purposes.

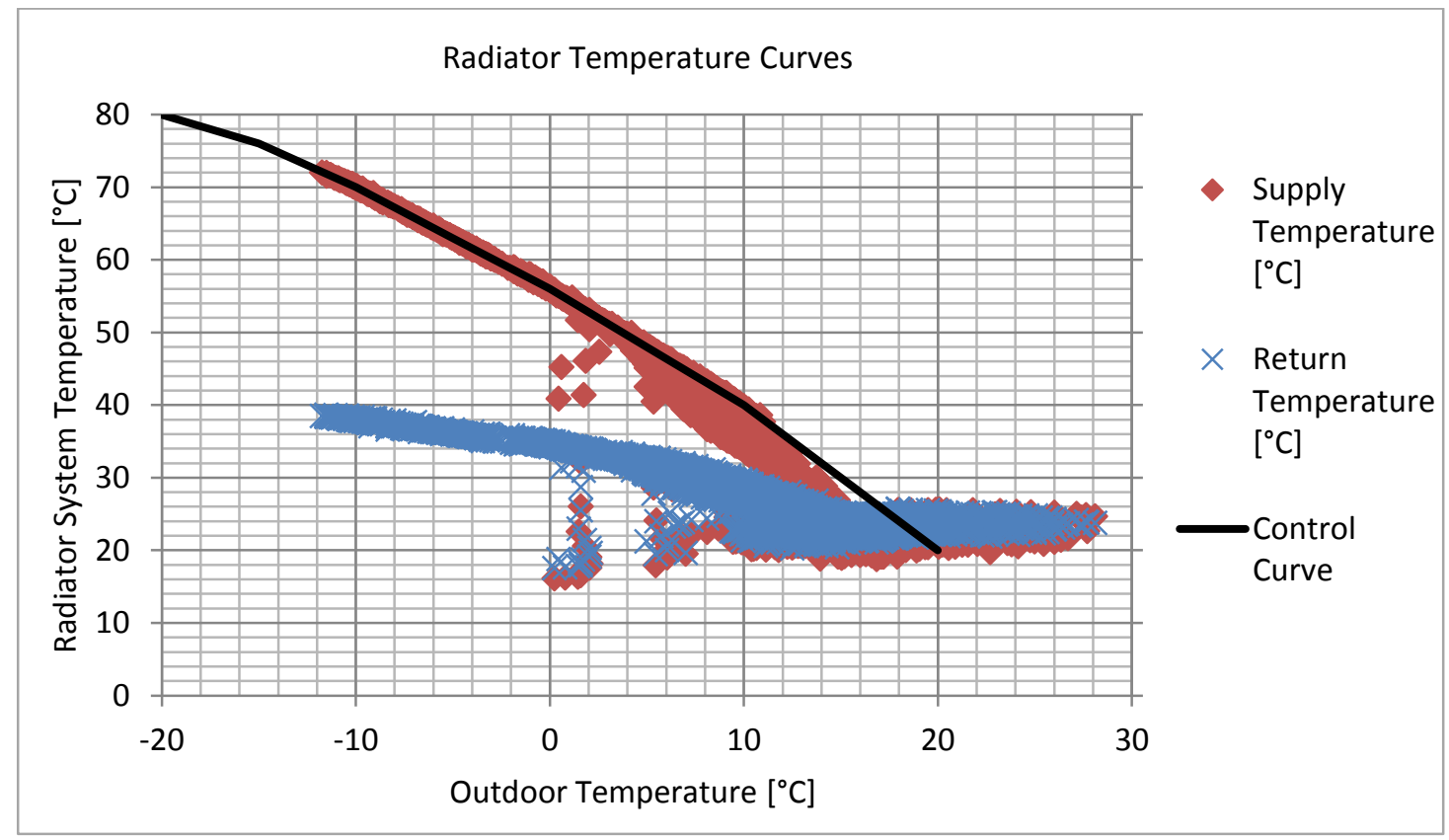

Figure 9: Temperature curve plot of radiator system revealing recorded temperature measurements deviation from normal operation for some outdoor temperatures. This deviation is most likely due to a radiator circulation pump stop since both radiator supply and return temperatures have decreased for the corresponding outdoor temperatures.

\subsection{Radiator System Temperatures}

In the following section the results of the survey of the radiator temperatures are presented. For DOT, which is $-16^{\circ} \mathrm{C}$ in Gothenburg, the average supply and return temperatures are 64 and $42^{\circ} \mathrm{C}$. The annual average temperatures in the radiator systems are $46^{\circ} \mathrm{C}$ supply and $34^{\circ} \mathrm{C}$ return.

In Figure 10 and Figure 11 to follow the supply and return temperatures of the radiator systems surveyed are presented for seven different outdoor temperature categories. For each outdoor temperature category, the average values are shown with a cross and the median values are shown as the midline. The lower part of the box represents the first quartile and the upper part the third quartile. The bottom whisker is the local minimum and the top whisker the local maximum, where the values in between the end of the whisker and bottom of the box are part of the lowest $25 \%$ of the values in the data set, and the values between the top of the box and the upper whisker are part of the top 25\% of the temperature values. The outliers are represented with dots located outside the local minimum and maximum and are values corresponding to 1.5 times the interquartile range below and above the lower and upper quartiles respectively. The average values have not been weighted based on the size of the radiator system, but each temperature value is given the same significance. For each outdoor temperature category, the sample size is 109 , except for $\mathrm{T}_{\text {out }}=15^{\circ} \mathrm{C}$ where the sample size is 107 due to absence of heating need for two systems for that outdoor temperature. 
For the seven outdoor temperature categories, increments of 5 degrees were chosen since the radiator supply temperature control curves have different set points for each of these intervals. Although the control curves have set points for an outdoor temperature of $-20^{\circ} \mathrm{C}$, and some for $-30^{\circ} \mathrm{C}$ as well, $-16^{\circ} \mathrm{C}$ was chosen to represent the lowest outdoor temperature category since this is a common DOT for Gothenburg. Most of the radiator supply temperature control curves also have set points for outdoor temperatures of $20^{\circ} \mathrm{C}$, but since the majority of the radiator system circulation pumps stop the operation for outdoor temperatures between 15 and $17^{\circ} \mathrm{C}$, a maximum of $15^{\circ} \mathrm{C}$ was therefore chosen to be displayed.

For the outdoor temperature $-16^{\circ} \mathrm{C}$ the supply temperatures according to Figure 10 vary between a maximum value of $81^{\circ} \mathrm{C}$ and a minimum of $53^{\circ} \mathrm{C}$, with the average value being equal to $64^{\circ} \mathrm{C}$. The first and third quartile values are 61 and $66^{\circ} \mathrm{C}$ respectively for the DOT.

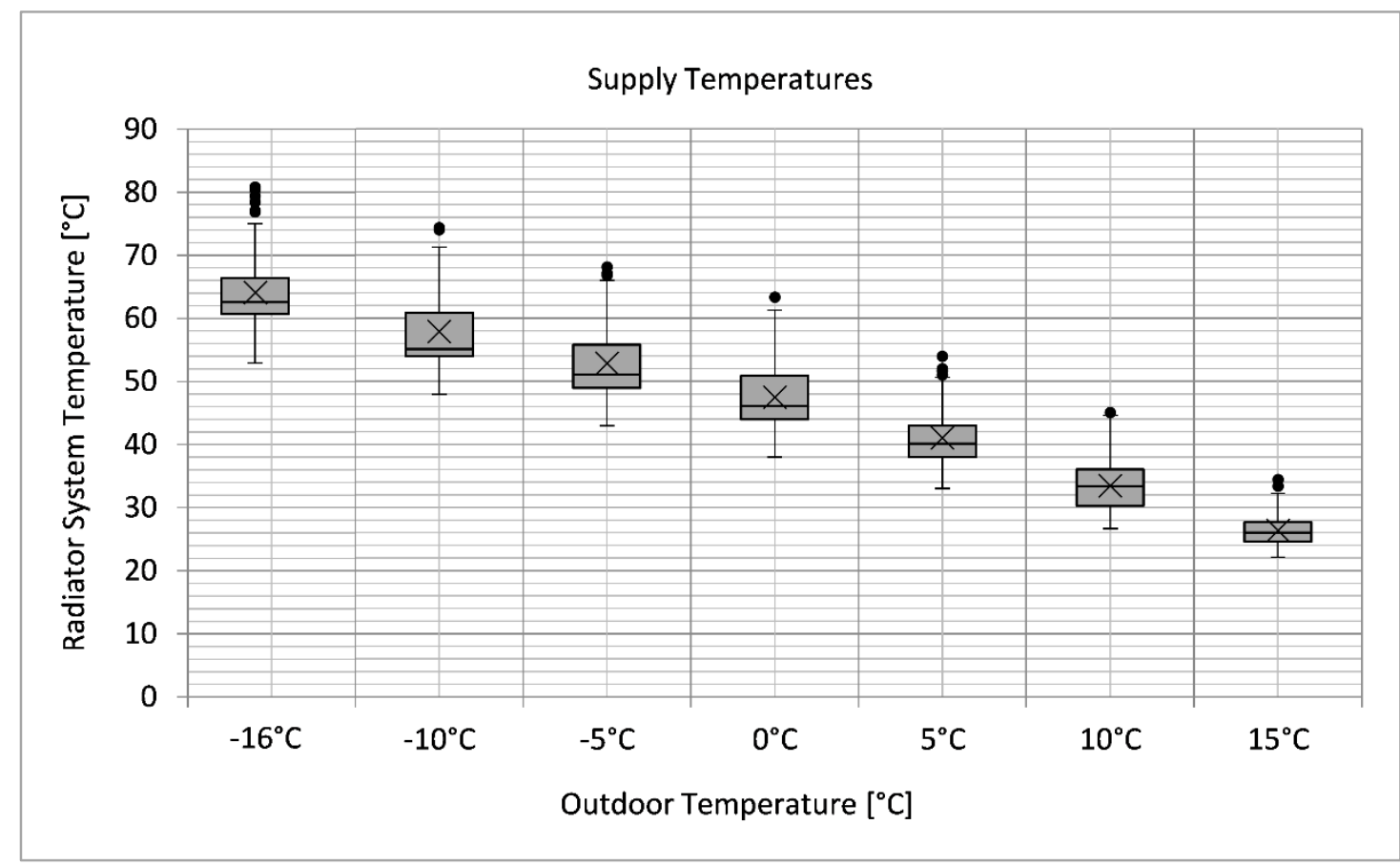

Figure 10: Box plot of the radiator supply temperatures encountered in the systems surveyed, varying for different outdoor temperature categories. The average values are shown with a cross and the median values are represented by the midline. The lower part of the box represents the first quartile and the upper part the third quartile. The bottom whisker is the local minimum and the upper whisker is the local maximum. The outliers are represented with dots. $N=109$ for $T_{\text {out }} \leq 10^{\circ} \mathrm{C}$ and $N=107$ for $T_{\text {out }}=15^{\circ} \mathrm{C}$.

The actual supply temperatures in Figure 10 were verified with the intended ones according to the supply temperature control curves at DOT. It was found that for six of the systems the actual supply temperatures are 0.5 degrees or more, lower than the set points, whereas for twelve of the systems the actual supply temperatures are 0.5 degrees or more above the intended temperatures according to the set points. Notable is that the three highest supply temperatures encountered in all radiator systems surveyed were almost four degrees higher than the intended temperatures according to their control curve set points. A possible reason to the deviation is that the radiator systems have a difficulty meeting the building heating demand, hence the supply temperatures have been increased by manual adjustment of the control system set points. Oppositely, for the systems where the actual supply temperature is lower than the set point values the 
heating demand is fulfilled with lower supply temperatures than the predefined set points.

The return temperatures varying for different outdoor temperature categories can be seen in Figure 11 . At DOT, $-16^{\circ} \mathrm{C}$, they vary from a maximum of $57^{\circ} \mathrm{C}$ to a minimum of $28^{\circ} \mathrm{C}$, with $42^{\circ} \mathrm{C}$ as the average. The values for the first and the third quartiles at DOT are 38 and $45^{\circ} \mathrm{C}$ respectively. The lowest return temperatures encountered for each outdoor temperature category all belong to the same radiator system.

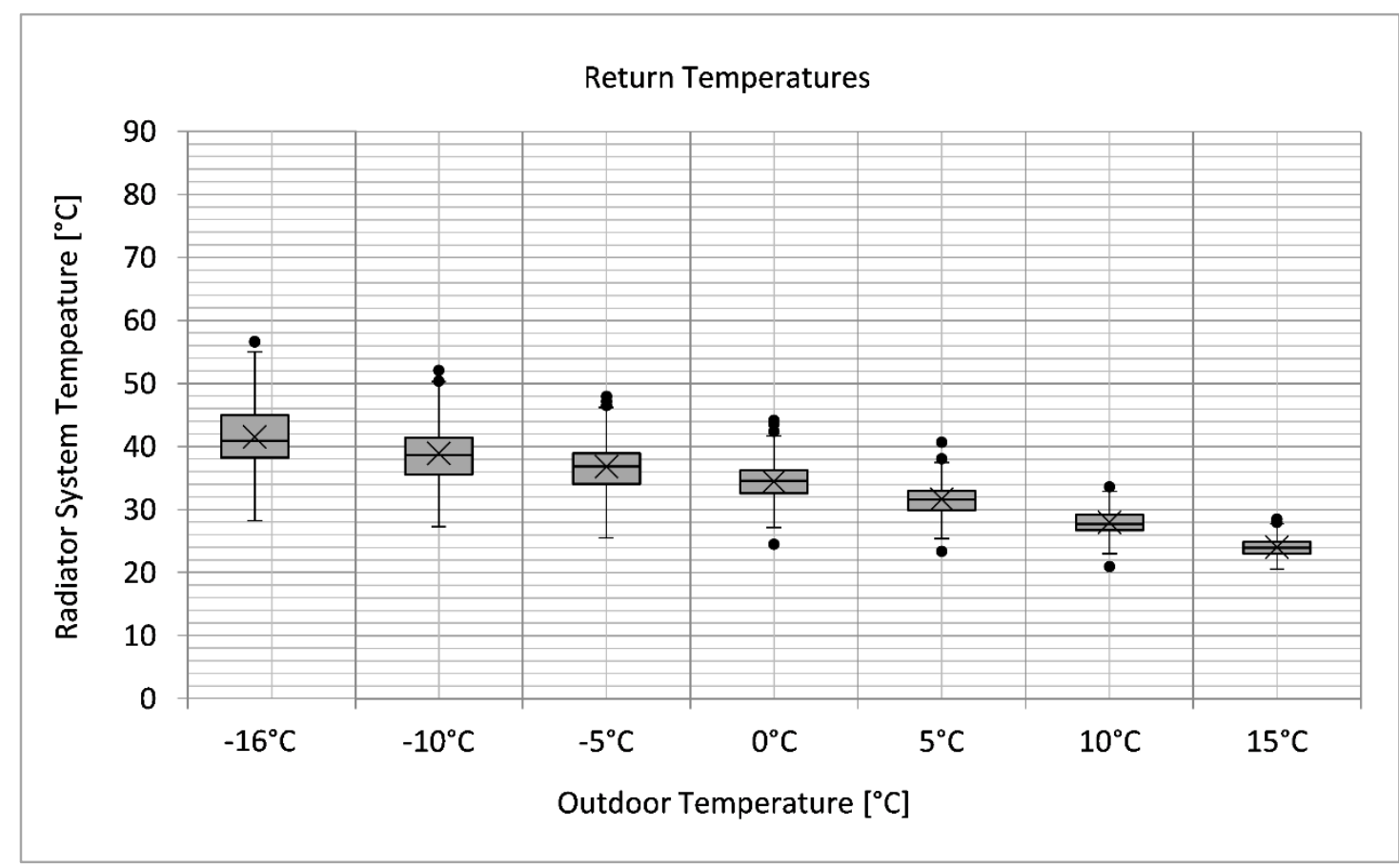

Figure 11: Box plot of the radiator return temperatures in the systems surveyed, varying for different outdoor temperature categories. The average values are shown with a cross and the median values are represented by the midline. The lower part of the box represents the first quartile and the upper part the third quartile. The bottom whisker is the local minimum and the upper whisker is the local maximum. The outliers are represented with dots. $N=109$ for $T_{\text {out }} \leq 10^{\circ} \mathrm{C}$ and $N=107$ for $T_{\text {out }}=15$.

\section{Compliance with Kärkkäinen Temperature Curves}

The relationship between supply and return temperatures and the outdoor temperature can be identified as a piecewise linear relationship according to Figure 10 and Figure 11 , which seems reasonable since the control of the radiator supply temperature is arranged accordingly, as described in section 2.2.5.

In Figure 12 the temperature curves by Kärkkäinen, also described in section 2.2.5, are shown along with the superimposed average supply and return temperatures obtained in this survey. As can be seen, the curves agree until an outdoor temperature of $15^{\circ} \mathrm{C}$ is reached, which is one way of verifying the results of the survey with theory. However, for outdoor temperatures greater than $15^{\circ} \mathrm{C}$, the radiator temperature curves from the survey start to deviate from the Kärkkäinen temperature curves. This could be explained by the fact that the average supply and return temperatures for the surveyed radiator systems are accumulated for all different radiator systems and building types, where the majority of the buildings part of the survey have balance temperatures between 15 and $17^{\circ} \mathrm{C}$. The Kärkkäinen curves, on the other hand, reflect the temperatures of one radiator with a balance temperature corresponding to $17.5^{\circ} \mathrm{C}$. 


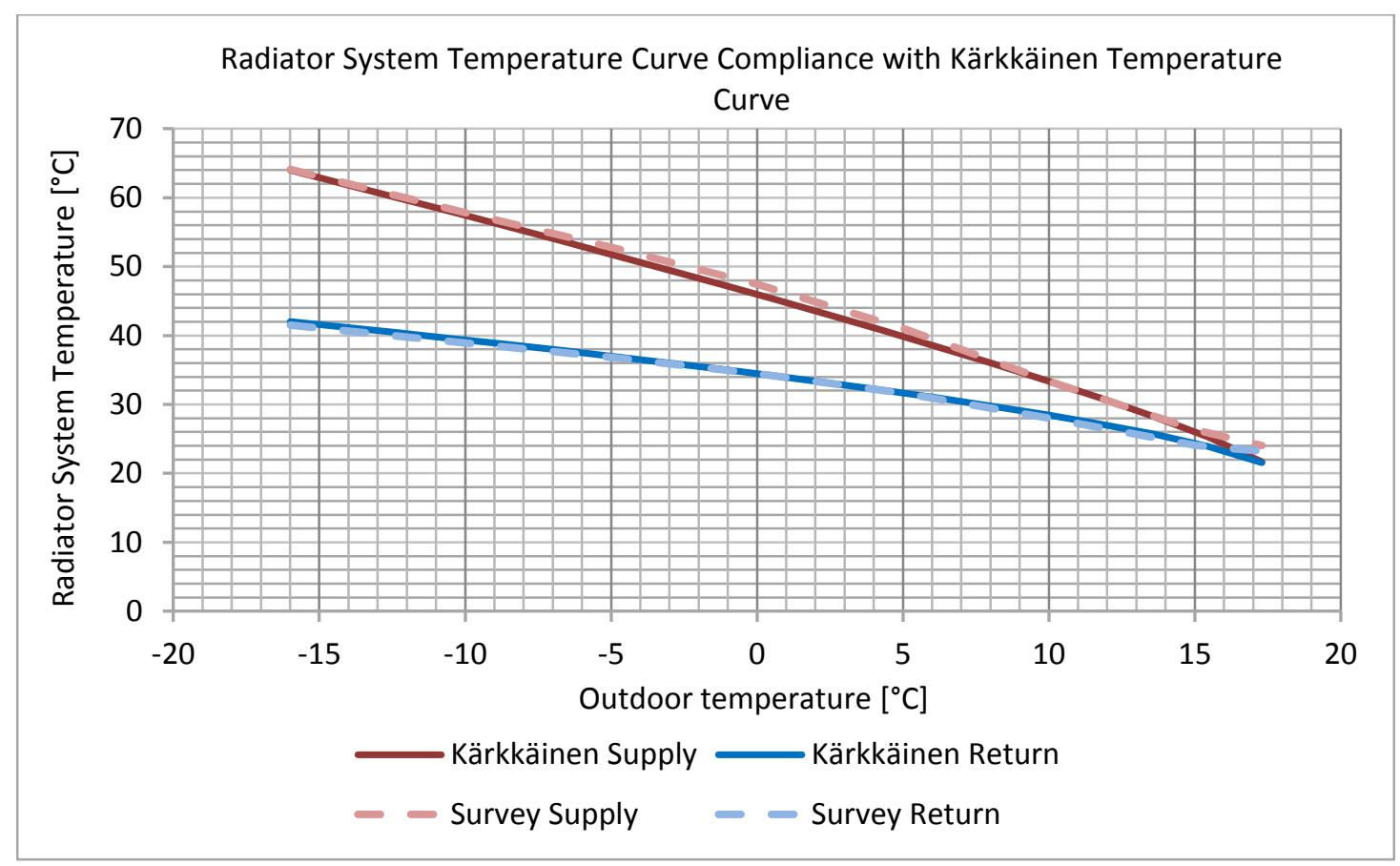

Figure 12: Average supply and return temperatures in the radiator systems part of the survey superimposed on the supply and return temperature curves by an explicit expression of (Kärkkäinen, 2010). The series "Kärkkäinen Supply" and "Kärkkäinen Return" represent the radiator temperature curves as a function of the outdoor temperature obtained from Kärkkäinen's explicit expression, which is based on a linear relationship between the radiator heat output and the temperature difference between supply and room temperature when the radiator water flow is constant. The series "Survey Supply" and "Survey Return" represent the temperature curves based on the results of this study for all systems surveyed $\left(N=109\right.$ for $T_{\text {out }} \leq 10^{\circ} \mathrm{C}$ and $N=107$ for $\left.T_{\text {out }} \geq 15^{\circ} \mathrm{C}\right)$.

\subsubsection{Temperature Difference in the Radiator Systems}

The supply and return temperatures from Figure 10 and Figure 11 have in Figure 13 been combined in order to show what the temperature differences in the radiator systems are. This was done since the temperature difference reveals information about how well the radiator system performs. The temperature difference also reveals information about potential balancing method utilized.

The temperature difference, $\Delta \mathrm{t}_{\mathrm{SH}}$, are shown in Figure 13 for the different outdoor temperature categories. As can be seen, in particular for the DOT, the range of temperature differences encountered in the radiator systems is widespread. For the temperature categories $-16,-10$ and $-5^{\circ} \mathrm{C}$ the average temperature differences in the radiator systems are 23,19 and $16^{\circ} \mathrm{C}$ respectively. However, worth mentioning are the largest values encountered, which are 47,34 and $29^{\circ} \mathrm{C}$ respectively. These are found in two specific radiators systems which serve different parts of the same building. These systems have supply temperatures around $80^{\circ} \mathrm{C}$ for DOT and corresponding return temperatures of $33^{\circ} \mathrm{C}$, leading to the presumption that the utilized balancing method is the low flow method, hence explaining the high supply temperatures encountered. 


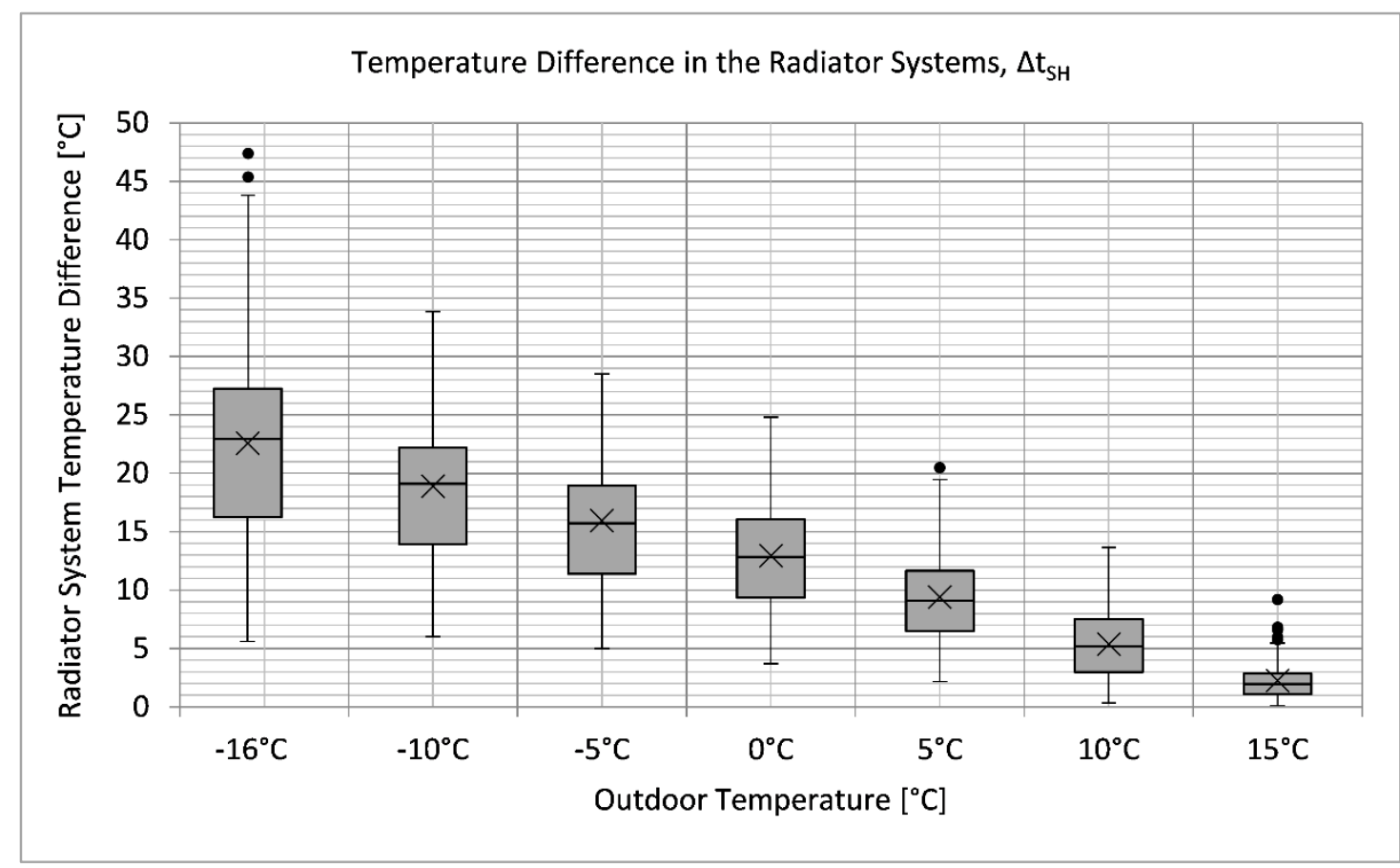

Figure 13: Temperature difference between supply and return in the radiator systems, $\Delta t_{s H}$, varying for different outdoor temperatures. The average values are shown with a cross and the median values are represented by the midline. The lower part of the box represents the first quartile and the upper part the third quartile. The bottom whisker is the local minimum and the upper whisker is the local maximum. The outliers are represented with dots. $N=109$ for $T_{\text {out }} \leq 10^{\circ} \mathrm{C}$ and $N=107$ for $T_{\text {out }}=15^{\circ} \mathrm{C}$.

For the next three outdoor temperature categories, 0,5 and $10^{\circ} \mathrm{C}$ the average temperature differences are 13,9 and $5^{\circ} \mathrm{C}$. Again, the largest values for these three categories, which are equal to $25,21,14^{\circ} \mathrm{C}$, all belong to a different radiator system. This radiator system is probably also balanced with the low flow method, but it also has a fairly large $\Delta \mathrm{t}_{\mathrm{SH}}$ for outdoor temperatures around, and even above, the building balance temperature. This is not the case for the majority of the systems investigated, which could indicate that the balance temperature (which determines the radiator circulation pump stop) may be set too low. If there is still a significant $\Delta t_{\text {SH }}$ for temperatures equal to or above the building balance temperature, it means that there is still a heating need despite the outdoor temperature reaching the predetermined building balance temperature.

For the outdoor temperature category $15^{\circ} \mathrm{C}$, which for many of the radiator systems surveyed is the set point for circulation pump stop (the same as the building balance temperature), the average $\Delta \mathrm{t}_{\mathrm{SH}}$ is $2^{\circ} \mathrm{C}$, and largest the temperature difference is $9^{\circ} \mathrm{C}$. The largest value for $\mathrm{T}_{\text {out }}=15^{\circ} \mathrm{C}$ is found in a radiator system different than for the other temperature categories. For this particular system the supply temperatures are consistently 5 degrees higher than those of the control curve set points, and because of this it can be assumed that the heat demand cannot be met with the prevailing set points on the control curve, hence resulting in a need for elevated supply temperatures. This could be a reason that more heat is needed and therefore a larger temperature difference is found for $15^{\circ} \mathrm{C}$ outdoor temperature compared to the other radiator systems.

As shown in Figure 13 the temperature differences in the radiator systems surveyed vary considerably, and there is a significant difference between the average $\Delta \mathrm{t}_{\mathrm{SH}}$ values and the maximum $\Delta \mathrm{t}_{\mathrm{SH}}$ values for all outdoor temperature categories. For outdoor temperatures greater than $-16^{\circ} \mathrm{C}$, where the heat loads will be partial, a temperature optimization of the radiator systems, as described in section 2.2 .3 , could potentially be 
done. The optimization is done by adjustment of the radiator water flow rates for different outdoor temperatures in order to achieve a more optimal supply temperature, and $\Delta \mathrm{t}_{\mathrm{SH}}$ will as a result increase. For $-16^{\circ} \mathrm{C}$, where the heat loads should correspond to those the radiator systems have been designed for, the temperature difference has been further examined as a function of the supply temperature. This is shown in Figure 14, where the size of the data points represents the heating usage by each radiator system in $\mathrm{MWh} /$ year.

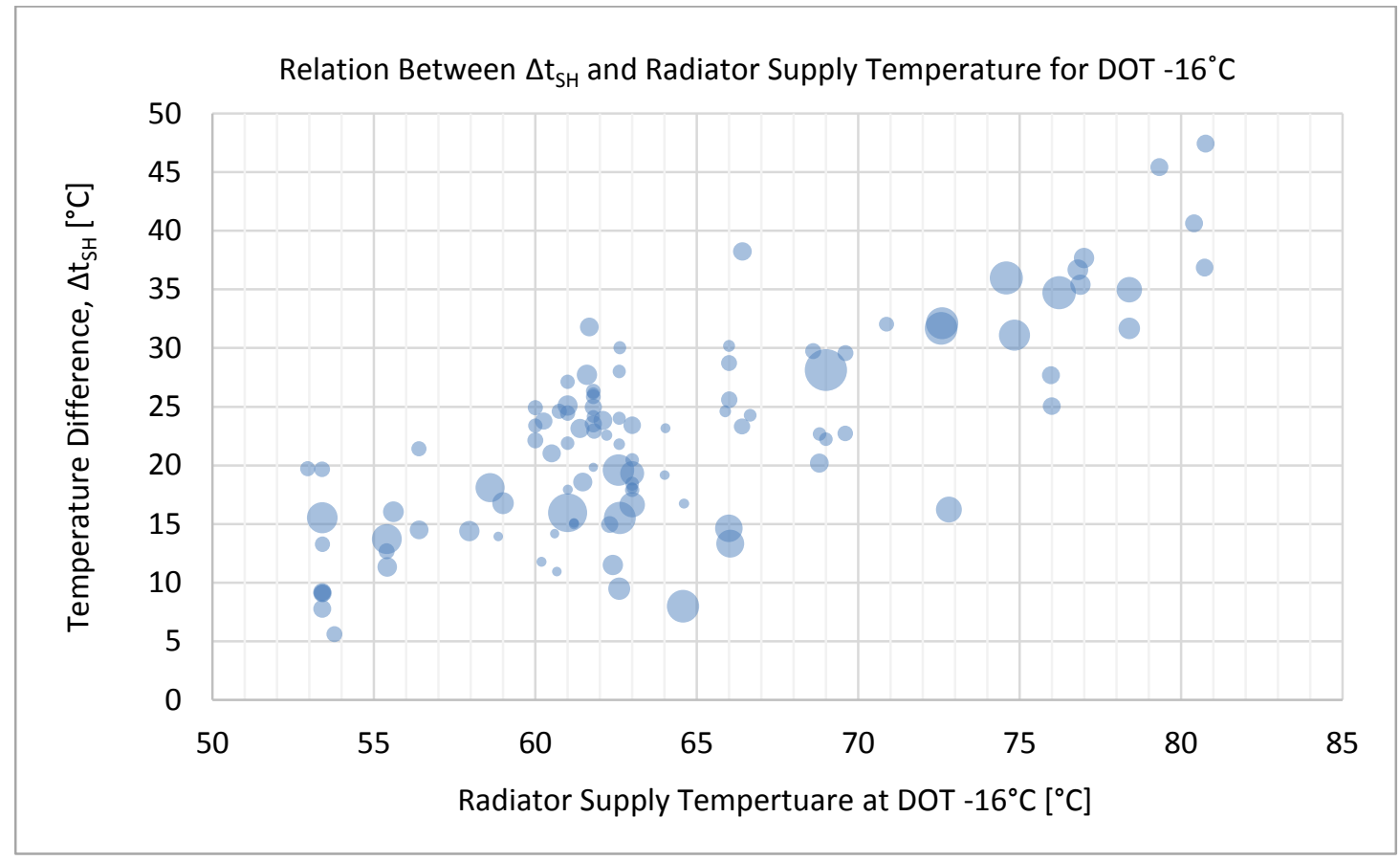

Figure 14: Radiator temperature difference between supply and return, $\Delta t$ tsh, as a function of the radiator supply temperature for DOT $=-16^{\circ} \mathrm{C}$. The size of the data points represents the space heating usage for each radiator system.

The majority of the radiator systems $(62.5 \%)$ have supply temperatures between 60 and $70^{\circ} \mathrm{C}$ at $-16^{\circ} \mathrm{C}$. In $20 \%$ of the systems the supply temperatures are lower than $60^{\circ} \mathrm{C}$ and for $17 \%$ of the radiator systems the supply temperatures are greater than $70^{\circ} \mathrm{C}$. The radiator systems with a larger temperature difference also have higher supply temperatures and vice versa. For instance, radiator systems with supply temperatures of $60^{\circ} \mathrm{C}$ or lower all have a temperature difference of less than $22^{\circ} \mathrm{C}$ at DOT.

As can be seen in Figure $14, \Delta \mathrm{t}_{\mathrm{sH}}$ varies from a minimum of $5.6^{\circ} \mathrm{C}$ up to $47.4^{\circ} \mathrm{C}$. This difference also reveals some information about what balancing method that has been utilized in the radiator systems. Based on the theory in section 2.2.3., a temperature difference between the supply and return side of $40^{\circ} \mathrm{C}$ or more is typical for the low flow method and for the high flow method the temperature difference should be $20^{\circ} \mathrm{C}$ or less. Based on this, $41 \%$ of all radiator systems have been balanced with the high flow method and $3 \%$ with the low flow method. The remaining $56 \%$ have consequently been balanced with something in between the low and the high flow method, which is also what Bostads AB Poseidon typically utilizes when balancing their systems today. However, this does not account for any systems that may actually not be balanced at all, or for any deterioration to the intended system operation since last time of balancing, potentially leading to temperatures different than those obtained initially. This means that some systems could originally have been balanced with a certain method, but due to alterations to system operation, a modified temperature difference than those 
intended at the time of balancing may be present. This could be a reason behind the average temperatures encountered in the radiator systems according to Figure 10 and Figure 11 being $64^{\circ} \mathrm{C}$ supply and $42^{\circ} \mathrm{C}$ return at DOT when the typical temperatures utilized when balancing the systems are 60 and $40^{\circ} \mathrm{C}$ respectively for DOT.

\subsection{Factors Affecting the Radiator Temperatures}

In order to evaluate potential factors affecting the temperature levels in the radiator systems the following results have been produced. These results have also been correlated to a potential temperature reduction of the temperatures on both the $\mathrm{DH}$ and radiator system sides.

\subsubsection{Radiator Sizes}

As mentioned in Chapter 2 the degree of radiator over dimensioning is something affecting the temperature levels. In order to reveal information about potential over dimensioning, the radiator sizes have been investigated by calculating the normalized radiator constants, $\mathrm{K}_{\mathrm{rad}, \mathrm{n}}$, displayed in Figure 15 . The radiator constants vary from slightly above 1.0 down to $0.21 \mathrm{~W} / \mathrm{K}^{\mathrm{n}} \mathrm{m}^{2}$, with the average value being $0.61 \mathrm{~W} / \mathrm{K}^{\mathrm{n}} \mathrm{m}^{2}$. These values indicate the amount of heat delivered per degree temperature difference between the radiator supply water and the air temperature within the room per heated square meter.

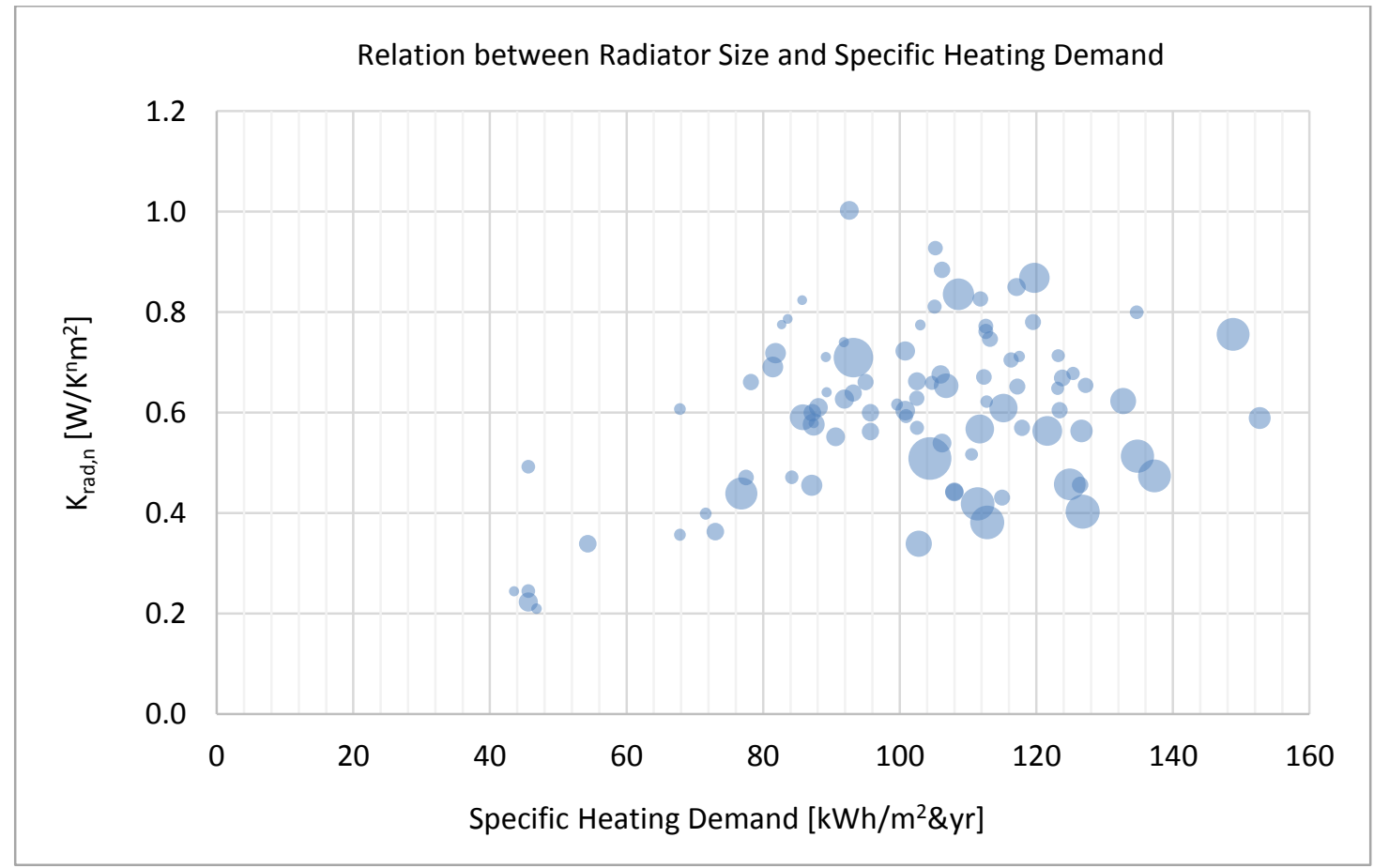

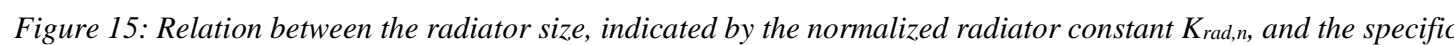
heating demand for the radiator systems surveyed. The y-axis shows the normalized radiator constant per square meter of heated area calculated at DOT, which is a measure of the amount of heat delivered per degree temperature difference between the radiator supply water and the air temperature within the room per heated square meter. The $x$-axis shows the specific heating demand per year for each radiator system. The size of the data points represents the system total space heating utilization during one year in MWh per radiator system.

For two of the four radiator systems with the lowest $\mathrm{K}_{\mathrm{rad}, \mathrm{n}}$ values in Figure 15, a radiator type different than the standard panel radiator is installed, as well as another pipe 
configuration than those found in the majority of the systems surveyed. Therefore, a skepticism of the applicability of Equation (2) is raised since that equation has been developed for panel radiators specifically. For the other two systems with the lowest $\mathrm{K}_{\mathrm{rad}, \mathrm{n}}$ values, heat pumps are installed in the radiator system resulting in a lower heating demand for large parts of the year compared to the other systems surveyed.

A large $\mathrm{K}_{\mathrm{rad}, \mathrm{n}}$ value indicates a large radiator heat transfer surface. This means that the potential of low operating temperatures at DOT, for example $60 / 30^{\circ} \mathrm{C}$ supply and return, is the greater than for systems with a low $\mathrm{K}_{\mathrm{rad}, \mathrm{n}}$. This is because low supply and return temperatures require a large radiator surface area in order to provide sufficient heat to the room. Conversely, low radiator constants imply that the radiator's heat transfer surfaces are small and would therefore require higher supply temperatures.

A building with a low specific heating demand also has a potential of lower operating temperatures, something that has been investigated in section 4.3.3 below. One way of examining the radiator systems with the greatest potential of lower operating temperatures is to divide the normalized radiator constants, $\mathrm{K}_{\mathrm{rad}, \mathrm{n}}$, with the building yearly specific space heating demand, QsH. In Figure 16 this relationship is plotted against the radiator supply temperatures at DOT, where a large $\mathrm{K}_{\mathrm{rad}, \mathrm{n}} / \mathrm{Q}_{\mathrm{sH}}$ value indicates a large radiator heat transfer surface or a low specific heating demand for the radiator system, or a combination of both.

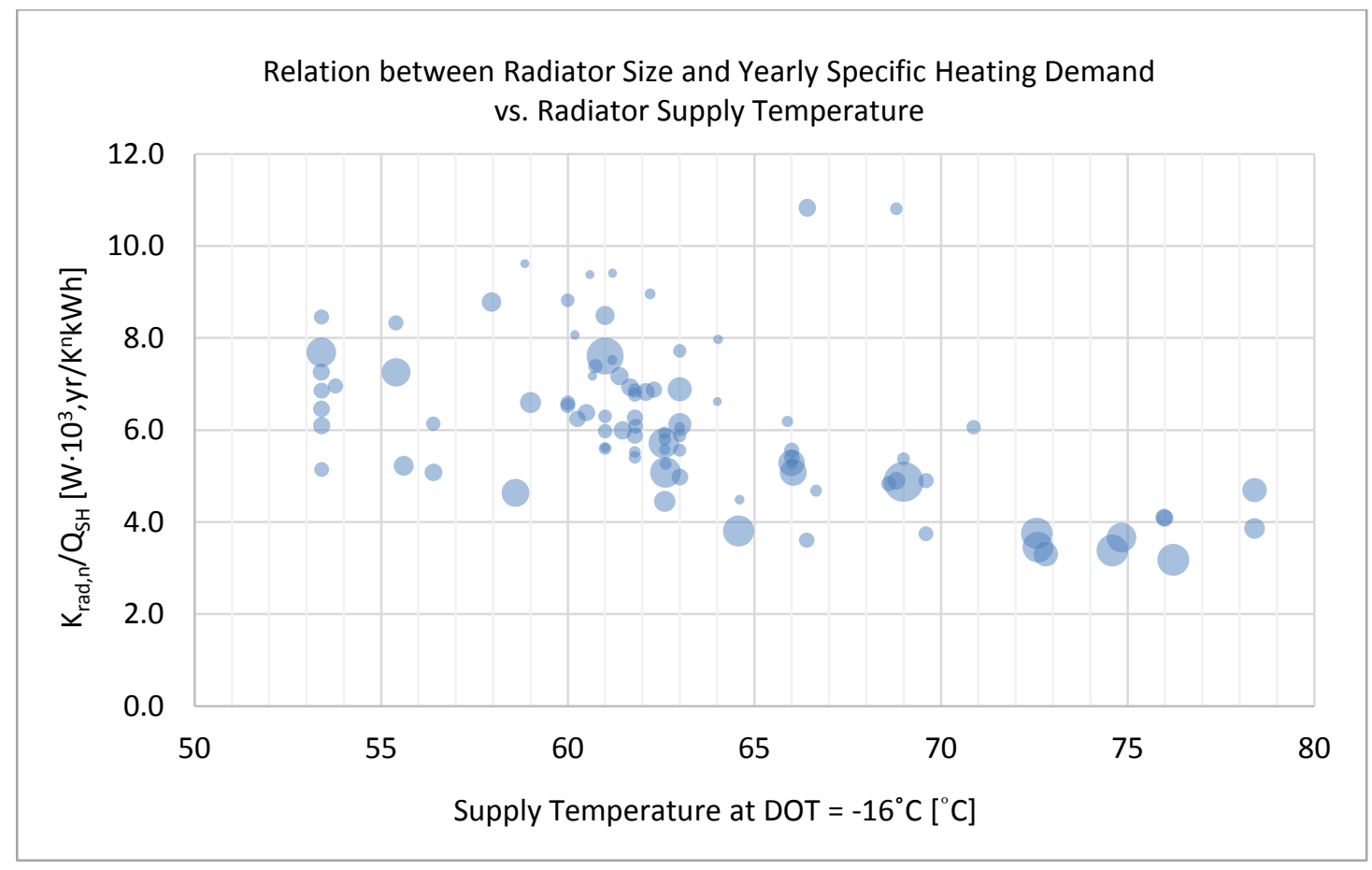

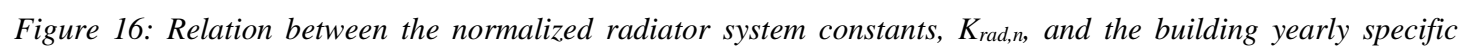
heating demand, $Q_{S H}$, plotted against the radiator system supply temperatures. A large $K_{\text {rad, }} / Q_{S H}$ indicates a large radiator size or a low specific heating demand for the radiator system, or a combination of the both. The radiator systems with the largest $K_{r a d, n} / Q_{S H}$ values have the greatest potential of lower operating temperatures.

As can be seen, there is a large spread of the radiator heat transfer area to specific heating demand, but a trend can be observed from approximately $\mathrm{T}_{\mathrm{rad}, \mathrm{s}}=60^{\circ} \mathrm{C}$ and up, where the radiator systems with a lower $\mathrm{K}_{\mathrm{rad}, \mathrm{n}} / \mathrm{Q}_{\mathrm{sH}}$ value also have the higher supply temperatures. However, an exception is observed for two systems where $\mathrm{K}_{\mathrm{rad}, \mathrm{n}} / \mathrm{Q}_{\mathrm{sH}}>$ $10 \mathrm{~W} \cdot 10^{3}, \mathrm{yr} / \mathrm{K}^{\mathrm{n}} \mathrm{kWh}$. These two radiator systems have the greatest potential of lower operating temperatures of the systems surveyed, possibly without any alternations to the building done. The systems with $\mathrm{T}_{\mathrm{rad}, \mathrm{s}}>65^{\circ} \mathrm{C}$ and $\mathrm{K}_{\mathrm{rad}, \mathrm{n}} / \mathrm{Q}_{\mathrm{sH}}<6 \mathrm{~W} \cdot 10^{3}, \mathrm{yr} / \mathrm{K}^{\mathrm{n}} \mathrm{kWh}$ 
have radiators most likely designed without any over dimensioning. This means that an increase of the heat transfer area in these systems would probably be necessary in order to reduce the temperatures, alongside a reduction of the heating demand. For the remaining radiator systems with $\mathrm{T}_{\mathrm{rad}, \mathrm{s}}<65^{\circ} \mathrm{C}$, it may be possible to achieve operating temperature reductions by either increasing the heat transfer surface or decreasing the space heating demand. However, both factors are important to consider if further investigations on potentially lower their operating temperatures are to be done.

\section{Potential of LTDH in the Radiator Systems Surveyed}

Low-temperature district heating (LTDH) is defined with operating temperatures of 55$50^{\circ} \mathrm{C}$ supply and $20-25^{\circ} \mathrm{C}$ return on the primary side of the DH system, see Chapter 1 . In order to potentially implement any reductions of the operating temperatures in the DH system the temperature difference across the heat exchanger between primary and secondary sides in the DH system, as described in section 2.1.4, as well as temperature losses in the distribution system need to be accounted for. Without further investigation on the required minimum temperature difference between the operating temperatures of the primary and secondary side, which is outside the scope of this study, the results of this study can be compared to the temperatures of LTDH.

It was found that $8 \%$ of the radiator systems have a supply temperature of $55^{\circ} \mathrm{C}$ or less at DOT. For the outdoor temperature category $0^{\circ} \mathrm{C}$ the share is increased to $87 \%$ and for the outdoor temperature category $5^{\circ} \mathrm{C}$ and above, all systems have a supply temperature of maximum $55^{\circ} \mathrm{C}$. The corresponding average return temperatures for the radiator systems with supply temperatures of $55^{\circ} \mathrm{C}$ or less are 42,34 and $32^{\circ} \mathrm{C}$ for each temperature category $-16,0$ and $5^{\circ} \mathrm{C}$. This shows that despite the radiator supply temperatures falling within the LTDH range, their corresponding return temperatures are not consistent with LTDH. If a temperature reduction on the DH side was to be implemented this could therefore mean that the temperature difference between supply and return sides would be too low in order for the DH system to operate well.

For the city of Gothenburg the outdoor temperature drops to $0^{\circ} \mathrm{C}$ or less for approximately 2 month of the year, and the amount of time with outdoor temperatures less than $5^{\circ} \mathrm{C}$ is slightly more than 5 months (Taesler, 1972). The results of this survey therefore indicate that there is a potential of lowering the supply temperatures in the DH system during large parts of the year.

\subsubsection{Building Construction Year}

Another factor potentially affecting the temperature levels of the radiator systems is the construction year of the building. In Figure 17 the construction year of the buildings, categorized per geographical area, can be observed for each radiator system supply temperature at DOT. A correlation between construction year and supply temperature was not found, although a tendency that the newer buildings have lower supply temperatures can be observed. However, renovation measures implemented from year of construction as well as modifications to the space heating systems, have not been accounted for in Figure 17, and could potentially serve as an explanation as to why the oldest building has one of the lowest supply temperatures. In Figure 17 it can also be noted that the highest supply temperatures, corresponding to $68^{\circ} \mathrm{C}$ or more, are found in the buildings constructed between 1950 and 1965. 


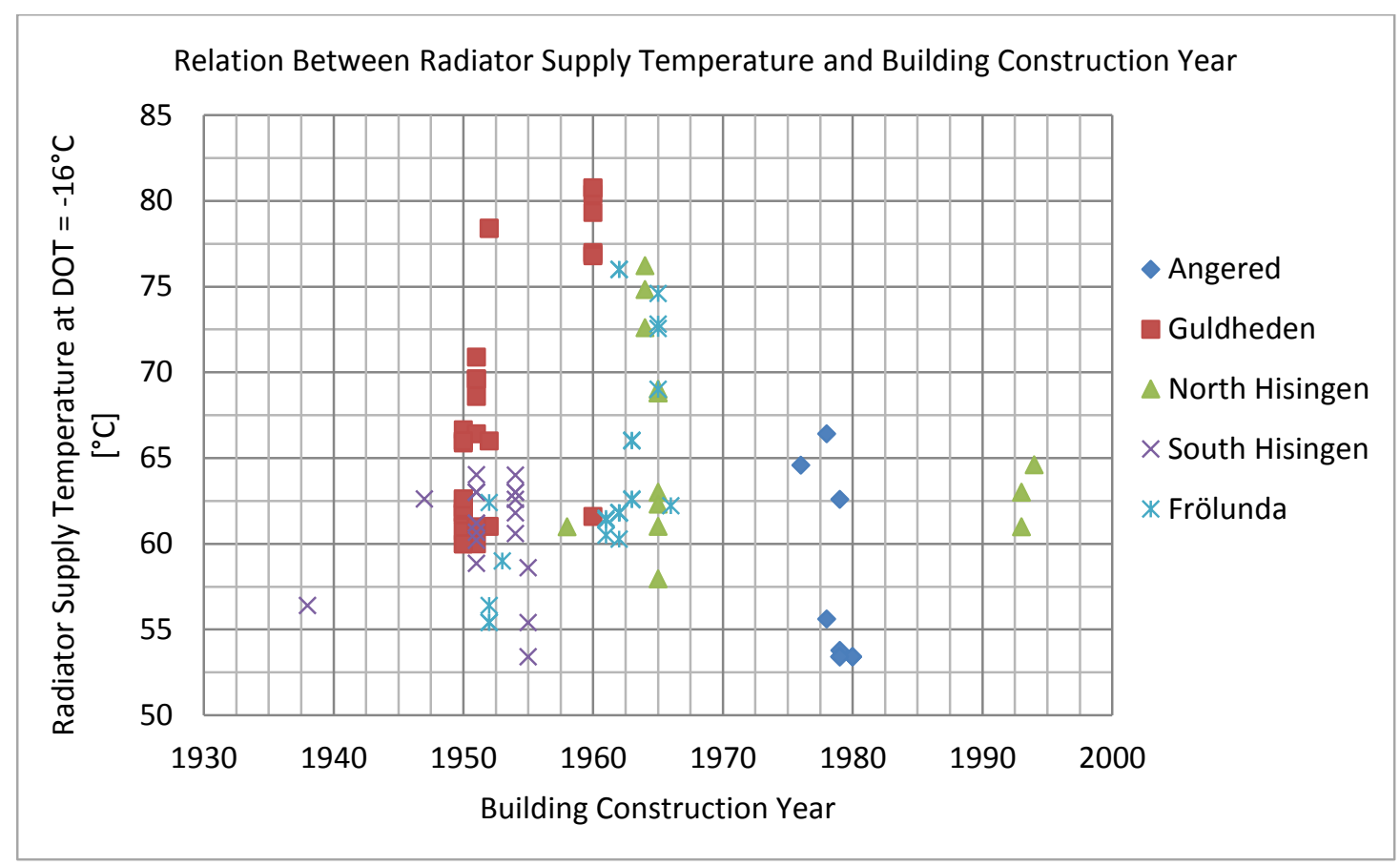

Figure 17: Relationship between the radiator supply temperature for $D O T=-16^{\circ} \mathrm{C}$ and the building construction year as encountered in the different geographical areas where the radiator systems part of the survey are located. Any renovation done to the buildings since year of construction has not been accounted for.

Something that can also be observed in Figure 17 is the spread of the supply temperatures in the different geographical areas where the radiator systems part of the survey are located. For example, in the area of Angered the buildings are constructed within the same years (between 1975-80) and also have similar radiator supply temperatures, although with a spread of 13 degrees. It can also be seen that the area of South Hisingen has the older buildings, but also some of the lowest supply temperatures, which could be an indication that upgrades have been made to the buildings in this area.

\subsubsection{Building Specific Space Heating Demand}

Potentially affecting the temperature levels in the radiator systems is the building's space heating demand. This is because if reduced, the radiator supply temperatures may have to be lowered in order to prevent overheating, see section 2.2.3. In Figure 18 the relation between radiator supply temperature and building specific heating demand per square meter heated area and year is shown, categorized per geographical area. A strong correlation between the two factors supply temperature and specific heating demand was not found to be significant, although there is a tendency towards higher supply temperatures in buildings with a higher specific heating demand and vice versa. What is interesting to note in Figure 18 is that the same specific space heating need is present in buildings where the lowest supply temperatures are encountered, as well as in buildings that have the highest supply temperatures, as found in this survey. 


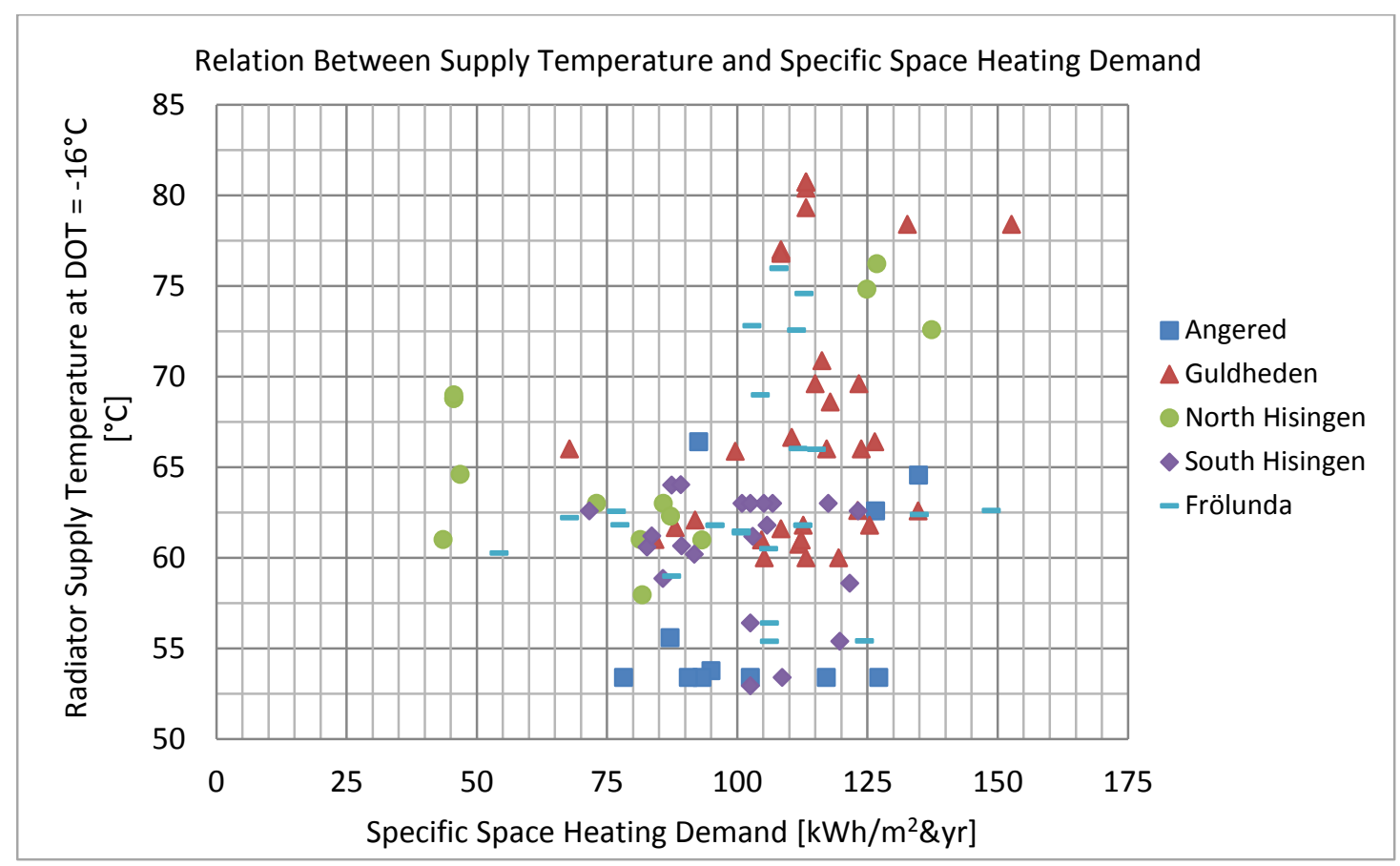

Figure 18: Relationship between radiator supply temperature for $D O T=-16^{\circ} \mathrm{C}$ and building specific space heating demand as encountered in the different geographical areas where the radiator systems surveyed are located.

The relation between supply temperature and specific space heating demand was categorized per geographical area surveyed in order to investigate any differences between the areas. The lowest space heating demands are found in the area of North Hisingen, however, some of the highest space heating demands are also present in the same area. This is because the three systems with the lowest space heating demands have heat pumps or heat recovery systems integrated to the radiator systems. The lowest supply temperatures are found in the areas Angered and South Hisingen, whereas the highest supply temperatures belong to the radiator systems located on Guldheden.

\subsubsection{Hydronic Balancing of Radiator Systems}

Another important factor affecting the temperature levels in the radiator systems is the balancing of them, see section 2.2.4. Most of the radiator systems part of this survey have been balanced, some more recently and some longer ago. In Figure 19 the temperature difference, $\Delta \mathrm{t}_{\mathrm{sH}}$, for eleven radiator systems in one of the districts are presented. The top of the bars are the supply temperatures and the bottom the return temperatures. Systems $1-3$, with $\Delta \mathrm{t}_{\mathrm{SH}}$ between $16-38{ }^{\circ} \mathrm{C}$, were balanced between 2013 2014 and the remainder has not been balanced recently, if even at all. 


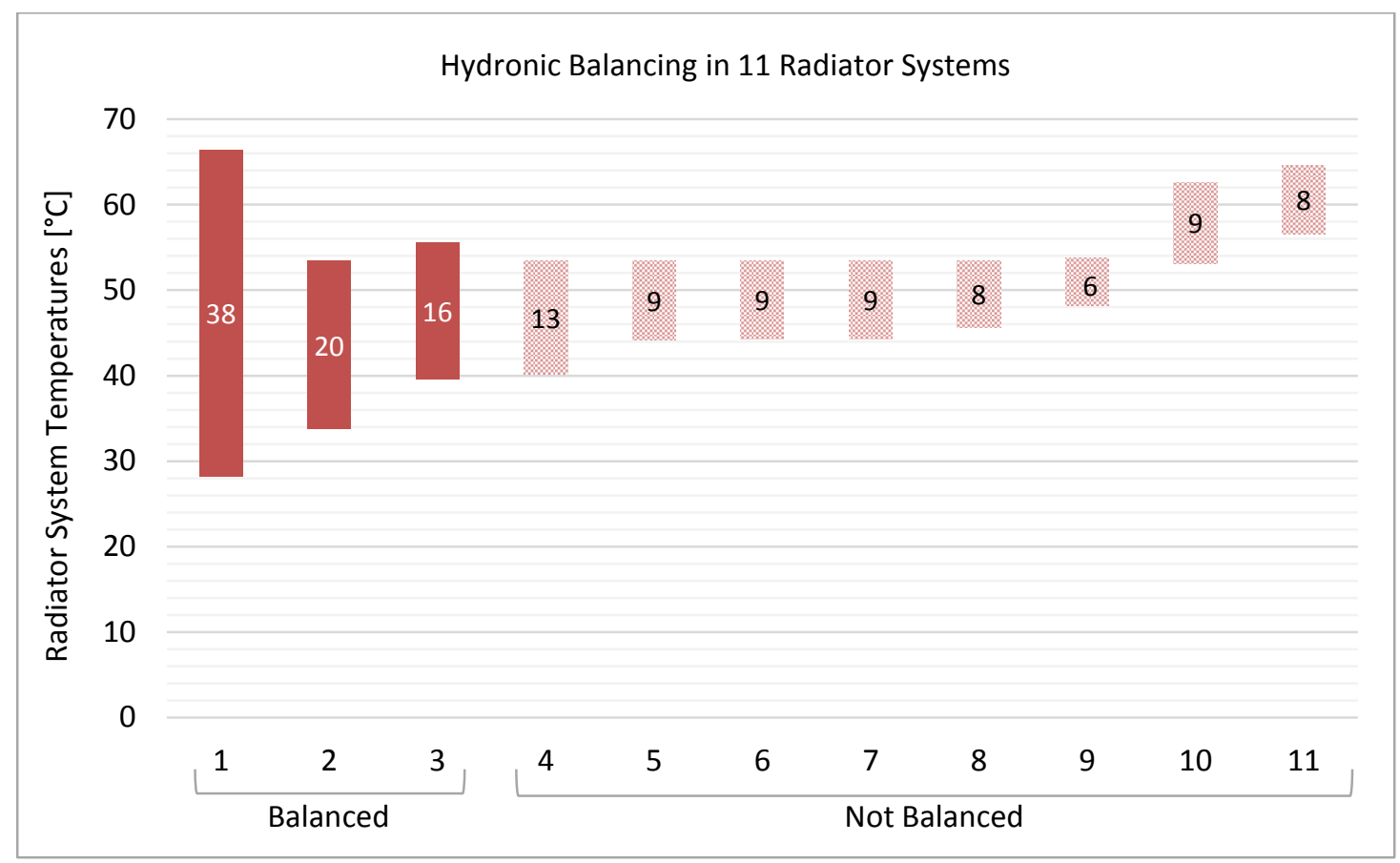

Figure 19: The effect on radiator temperatures from hydronic balancing of the radiator system. The temperature differences between supply and return sides are shown for 11 different radiator systems located in the same geographical area where hydronic balancing recently has been done for systems 1-3, but not for systems 4-11. The top of the bar represents the supply temperature and the bottom of the bar the return temperature in each radiator system. The numbers inside each bar indicate the temperature difference in degrees Celsius between supply and return.

Despite the information available to investigate the effect of balancing being minimal, Figure 19 indicates that balancing of the radiator systems does not necessarily generate low supply temperatures, but instead lower return temperatures, creating a larger temperature difference, $\Delta \mathrm{t}_{\mathrm{sH}}$, compared to radiator systems that have not been balanced. Similar trends could be observed in some of the systems in the other geographical areas as well, but the information available was too vague for any conclusions to be drawn.

\subsection{Temperatures on the Primary Side of the DH System}

In addition to measuring the temperatures on the $\mathrm{SH}$ side, $\mathrm{DH}$ water temperature data was also available for each radiator system. In Figure 20 the annual average supply and return temperatures of the primary $\mathrm{DH}$ side as recorded in the substations (see $\Delta \mathrm{t}_{\mathrm{DH}}$ in Figure 1) are presented. The top and the bottom of each bar represent the supply and return temperatures respectively. The temperatures on the primary side of the DH system vary slightly throughout the different geographical areas where the radiator systems part of the survey are located. The area with the highest annual average supply and lowest annual average return temperatures corresponding to 92 and $31^{\circ} \mathrm{C}$ are found in Angered. This is because Angered is located in the outskirts of the DH system and local heat generating units are supplementing the heat deliveries to this area. The primary DH temperatures are approximately the same for the remaining geographical areas, with annual averages of around $80^{\circ} \mathrm{C}$ supply and $34-39^{\circ} \mathrm{C}$ return. 


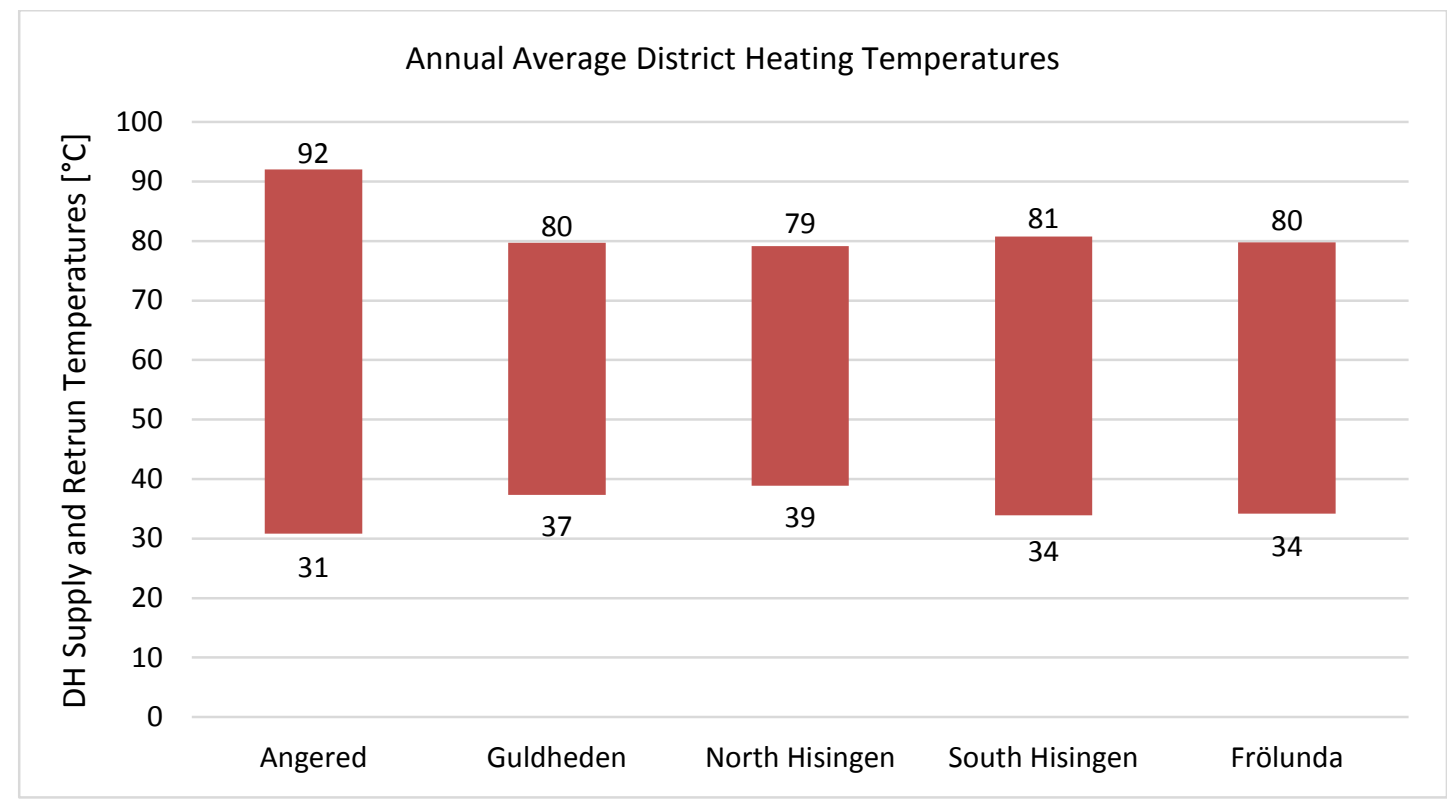

Figure 20: DH supply and return temperatures as recorded in the substations of the radiator systems in each of the five different geographical areas. The top of the bar, indicated with a number, represents the supply temperature and the bottom, also indicated with a number, represents the return temperature. All values are annual average values weighted equally throughout the year, including the non-heating season.

In Figure 2, Chapter 2, the benchmark supply temperatures as well as the customer guaranteed temperatures on the primary side of Gothenburg DH system are shown. Since the supply temperatures in Figure 2 vary with the outdoor temperature their corresponding annual average temperatures have to be calculated in order to be compared with the recorded $\mathrm{DH}$ temperatures presented in Figure 20. For the benchmark supply temperature, the annual average is calculated to be $82^{\circ} \mathrm{C}$ and the annual average customer guaranteed temperature is calculated to be slightly less than $77^{\circ} \mathrm{C}$. Comparing the annual average customer guaranteed supply temperature of $77^{\circ} \mathrm{C}$ to the annual average DH temperatures in Figure 20 it can be concluded that those are met in all geographical areas. For the annual average benchmark supply temperature on the other hand, this is only met in the area of Angered. However, it should be stressed that the values presented in Figure 20 are annual averages and also weighted equally throughout the year, including the non-heating season.

The temperatures on the primary side of the DH system can be compared to those encountered in the radiator systems on the secondary side in order to investigate the difference between the two sides. This could be interesting since as described in section 2.1.2 the temperatures generated on the primary side are sometimes unnecessarily high, in order to for example account for faults occurring in the substations. However, referring to section 2.1.4, a margin between primary and secondary sides is needed in order to ensure sufficient driving forces in the heat exchanger between the two sides. Also, potential temperature drops from the $\mathrm{DH}$ heat generating units to the end users need to be compensated for as well. To be able to compare the temperatures in Figure 20 with the annual average temperatures in the radiator systems Figure 21 was created. These annual average values can be compared to the average supply and return temperatures for all geographical areas combined, which is 64 and $42^{\circ} \mathrm{C}$ respectively when the outdoor temperature is equal to that of the DOT, $-16^{\circ} \mathrm{C}$ (see Figure 10 and Figure 11 in section 4.2). 


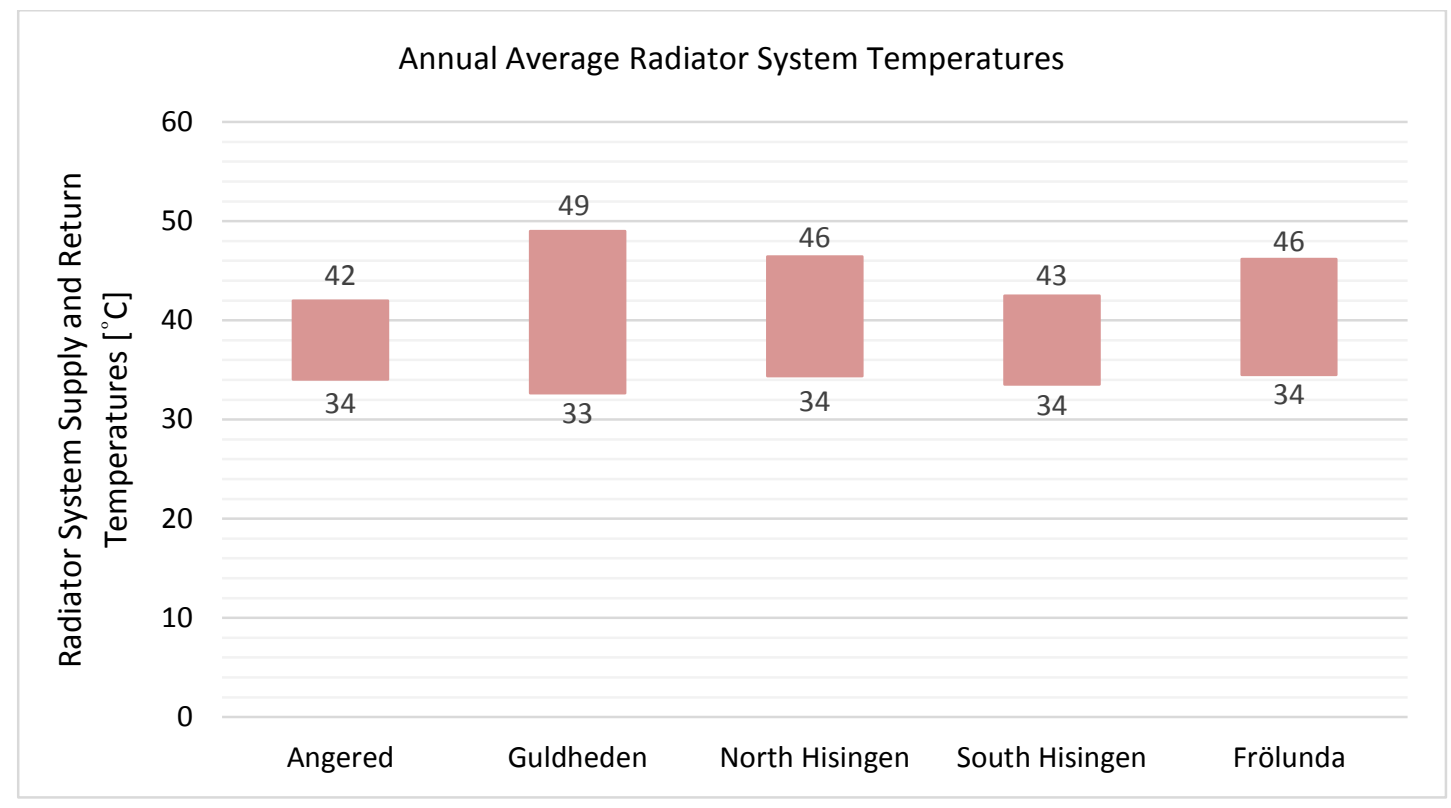

Figure 21: Annual average temperatures of the supply and return temperatures in the radiator systems as encountered in the different geographical areas. The top of the bar, indicated with a number, represents the supply temperature and the bottom, also indicated with a number, represents the return temperature. These annual average values can be compared to the average supply and return temperatures for all geographical areas combined of 64 and $42^{\circ} \mathrm{C}$ respectively for $D O T=-16^{\circ} \mathrm{C}$.

Comparing the supply temperatures in Figure 20 with those in Figure 21 is can be seen that the annual average difference in supply temperatures between the primary DH side and the radiator systems on the secondary side vary between 31 and 50 degrees depending on the geographical area. The highest margin between primary and secondary sides is found in the area of Angered where it is $50^{\circ} \mathrm{C}$.

It should be noted that since the values presented are based on annual averages, variations of the temperature margin between primary and secondary sides occur throughout the year, depending on the outdoor temperature. This has been investigated for in the area of Angered, see Figure 22. However, despite the outdoor temperature dependent variation in the temperature difference between DH and radiator sides, it is evident that this temperature difference is rather large during parts of the year. 


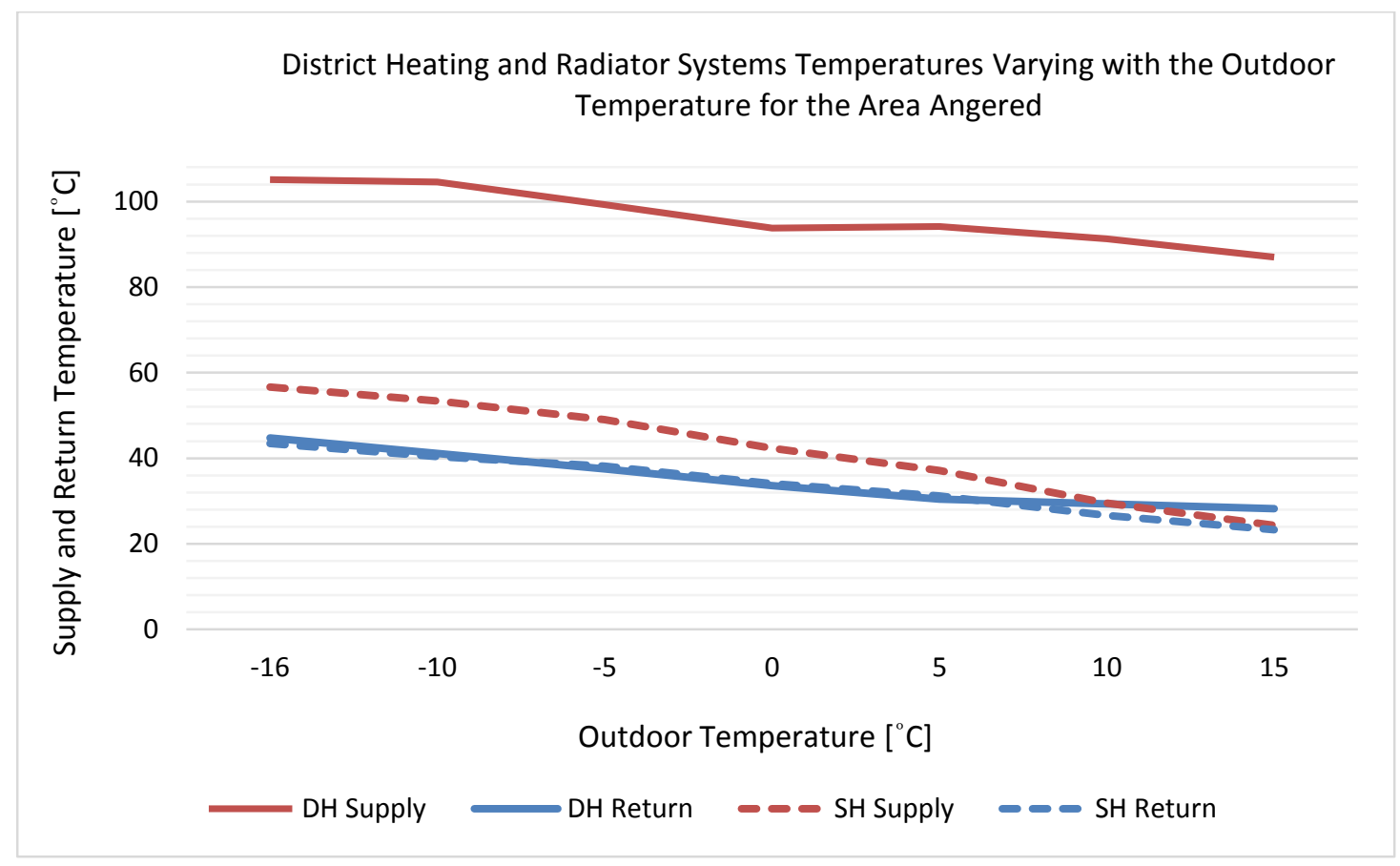

Figure 22: Supply and return DH and SH temperatures dependent on the outdoor temperatures as encountered in the radiator system substations in the geographical area of Angered. The DH supply and return temperatures are represented by solid lines and the SH temperatures with dotted lines. The temperatures are based on average values as recorded in the substations for each outdoor temperature category. $N=11$.

The area of Angered has the highest DH supply temperatures out of the geographical areas part of the study, which can be observed in Figure 20. It is also the area where the second lowest radiator supply temperatures at DOT were found, according to Figure 17. For an outdoor temperature of $-16^{\circ} \mathrm{C}$ the $\mathrm{DH}$ supply temperature is $105^{\circ} \mathrm{C}$, as can be seen in Figure 22. Compared to the maximum radiator supply temperatures for that area of $66^{\circ} \mathrm{C}$, the resulting temperature difference is $39^{\circ} \mathrm{C}$. 


\section{Discussion}

In the chapter to follow some aspects to a possible conformance with LTDH and the temperature levels defined for the $4 \mathrm{GDH}$ will be considered. Also, the validity of the results presented in the previous section will be discussed.

\subsection{Potential Temperature Reduction in the existing DH System}

As shown in Chapter 4 all radiator systems surveyed already partially operate with supply temperatures corresponding to those of LTDH. Additionally, a significant temperature difference between the primary side and the radiator systems was observed. This indicates a potential of lowering the supply temperature for parts of the year already today. However, there are many aspects that need to be taken into account if this is to be fulfilled, such as $\Delta t_{\mathrm{HEX}}$, distribution temperature losses, water flow rates and pressure levels. Also, depending on the DH system capacity and where any potential bottlenecks in the system are located, a temperature reduction during parts of the year may not be realistic.

The temperatures on the $\mathrm{DH}$ side need to be higher than the temperatures in the radiator systems in order to ensure sufficient driving forces in the heat exchanger between the primary side and the radiator systems. Despite efficient plate frame heat exchangers being available on the market today, a temperature drop between primary and secondary sides need to be allowed for. In existing buildings, the heat exchangers may be outdated and fouled which will produce a larger temperature drop than more modern heat exchangers. Another reason for the possibly excessive temperature difference between primary and secondary sides are due to malfunctioning operation of the DH system as well as substations and secondary systems. If sufficient temperature levels are provided the faults that occur will not lead to any customer discomfort or insufficient heat deliveries. However, if the temperatures are to be lowered many faults first need to be resolved. Not taken into account in this study is the DHW temperature need. If the DH supply temperatures are reduced (with the assumption that existing $\mathrm{SH}$ systems can allow for that), the DH system still needs to ensure that sufficient heat is delivered to meet the temperature demands of the DHW system as well.

The DH water flow rate is another important parameter when evaluating a potential DH temperature reduction. The heat demand in existing buildings is decreasing, but a concurrent increase of new customer connections leaves the net heat deliveries at unchanged levels. If the temperatures are lowered but the heat demands remain the same, the water flow rate will have to be increased. Depending on current system operation this could lead to water velocities exceeding the suggested threshold for noise limitation as well as undesirable large pumping costs could incur due to increased friction. Since the water velocity is proportional to the square root of the pressure difference, the pressure level is also a crucial parameter if the flow rates are altered. If the mass flow rate is to be increased without increasing the pipe diameter, the pressure drop in the flow direction will increase as well, something that has to be compensated for. Large operating pressures in the distribution pipelines lead to, among others, the necessity of careful valve handling in order to avoid water hammers.

This survey has only included a small amount of the radiator systems within the Gothenburg DH system. Customers with higher temperature needs than those that have been demonstrated in this study are likely to be present. To make sure all customers 
within the DH system will have their temperature requirements met, if the temperatures were to be lowered, a larger coverage of the customers' actual temperature needs will be of essence. Such coverage could be achieved by having the customers report their temperature requirements, something that could be incentivized in a similar way as the lowering of their return temperatures have been by the return fee.

In order for existing DH systems to adapt to the DH technology development and for the $4 \mathrm{GDH}$ to be progressively implemented, a potential solution could be to introduce LTDH in an area of new constructions. For such areas there is a potential to determine the specifications of the heating systems to be installed in advance, and therefore be able to control the resulting temperature needs of the entire area. The DH return pipes in the existing DH system could then serve as supply for such an area. This could be a viable solution to be implemented in a part of the existing DH system where the current capacity margins are low and new connections would require supplemental local generating capacity to be added.

To be able to implement LTDH in existing buildings the temperature demands present today need to be reduced. This can to a large extent be achieved by implementing energy savings measures which reduce the buildings' heat demands. However, it may in addition to this also be necessary to increase the heat transfer surface areas of the radiators in existing buildings so that sufficient heat can be delivered with lower operating temperatures, despite a reduction of the heat demand.

\subsection{Future DH Temperature Level Evaluation}

In order to develop the existing DH system to conform to the future 4GDH system the temperature levels are of essence. However, the proposed supply and return temperatures for 4GDH may not be the most optimal for existing DH systems. For example, as shown by Ommen, Markussen, \& Elmegaard (2016) the most optimal supply temperatures for one specific existing DH system evaluated for different future energy scenarios were $65-70^{\circ} \mathrm{C}$, from a cost perspective. Lower supply temperatures of $60^{\circ} \mathrm{C}$ lead to consumer temperatures of $55^{\circ} \mathrm{C}$ which then requires additional investments for booster heat pumps on the customer side to meet the temperature requirements for DHW, therefore resulting in a higher cost. However, the carbon dioxide emissions associated with heat generation was shown to be the lowest for supply temperatures of $50^{\circ} \mathrm{C}$.

For existing DH systems, where the transitioning to 4GDH may extend over a long period of time or even be implausible for some systems, there may instead be alternatives in order to enable a DH development incorporating temperature reductions and the integration of new alternative heat sources. One such example could be to consider potential prosumers, which is a DH customer that both uses and supplies heat. By examining the temperature needs of buildings in a certain area based upon the buildings' heating and cooling needs, potential prosumers can be identified within the area. This could be particularly useful for new areas within an existing DH system, such as discussed in section 5.1. In a study by Brange, Englund, \& Lauenburg (2016) the potential contributions by prosumers in a new development area part of the city Malmö, Sweden were investigated. The study showed that the prosumers could cover approximately $50 \%$ of the annual heat demand for the area in question. The remaining heat demand would originate from the existing Malmö DH system. The potential prosumer contributions are dependent upon a diverse heating and cooling need, hence 
for areas with a large share of residential buildings, where the heating need will dominate over the cooling need, the prosumer potential will decrease.

For that reason, depending on the possible prosumers, existing temperature demands as well as the operating conditions for the heat generation units within the conventional DH system, the most optimal supply and return temperature for a certain area can be found. Areas with a larger share of newly developed more energy efficient buildings may be suitable for the lower range of supply temperatures. Areas with mostly existing older buildings, where energy savings renovation measures have not yet been implemented, a high supply temperature need may prevail for some time to come, though with possible supply temperatures reductions for some durations of the year, when the space heating need is low.

Perhaps there should not be one overall fixed temperature target for the future generation of district heating incorporating the existing DH systems, but each DH system should be evaluated individually taking in mind not only consumers and DH generating units but also potential prosumers. In this way the most optimal operating temperatures can be achieved for each part of an existing DH system.

\subsection{Validation of Results}

\section{Radiator System Temperatures}

The radiator temperatures encountered in this survey are based on data from multifamily residential buildings owned and operated by the same public housing company and located within the same DH system. In order to validate the results and to be able to determine if the temperatures in Bostads AB Poseidon's radiator systems are typical or extraordinary, it would be of essence to compare the temperatures to those of a different housing company within the Gothenburg DH system. Additionally, the radiator temperatures encountered in multi-family buildings in a different DH system would have been interesting to compare the results of this study with. Such comparisons would aid the validation of the radiator temperatures encountered in this study.

In order to achieve a satisfactory statistical basis, radiator systems belonging to different areas of the Gothenburg DH system were selected as well as buildings with different construction years. Additionally, buildings with similar characteristics within the same area were selected to be part of the survey to the extent possible in order to increase the statistical significance for the types of buildings studied. Initially there were more systems included than those part of the results, but some of the data had to be eliminated due to different reasons. If this would not have occurred the statistical basis would have been approximately $20 \%$ larger. One reason to this elimination was due to the majority of a building being, for example, a premise with a different heating need to that of a typical residential building. For some of the buildings the data from one or several of the temperature sensors was not accessible or non-usable. Additionally, during the analysis of the radiator systems one system was identified to have a malfunctioning temperature sensor that gave unreasonable low return temperatures, and this system was therefore removed as well. However, for this reason there may be possibilities that other temperature sensors are faulty as well, somewhat distorting the results.

\section{Calculation of Supply and Return Temperatures at DOT}

Since measured values of the radiator temperatures at DOT were limited to only a few of the radiator systems, the supply and return temperatures had to be calculated for this 
outdoor temperature. The amount of data measurements that this calculation was based upon varied for each system, and was chosen so that the calculated supply temperature had the lowest deviation from the set point value. However, the corresponding value for the return temperature was based upon the same interval. Since there are no set points for the return temperature, that could be used for verification of the return temperature calculation at DOT, the return temperature calculations may not be based on the most optimal data measurement interval. Therefore, for some of the systems the obtained return temperature value may be different than what it would actually be if it instead had been recorded for $-16^{\circ} \mathrm{C}$.

\section{Average Temperatures for Different Outdoor Temperature Categories}

In Figure 10 and Figure 11 in Chapter 4 the average values for the supply and return temperatures are shown. For the lower outdoor temperatures, such as -10 and $-5^{\circ} \mathrm{C}$ the amount of hourly measurements was significantly less than for higher outdoor temperatures of 5,10 and $15^{\circ} \mathrm{C}$. The average supply and return temperature values for higher outdoor temperatures have therefore been based on a larger amount of measurements than the supply and return values for lower outdoor temperatures. The error margin for the lower outdoor temperatures is therefore expected to be larger than for the higher outdoor temperature categories. However, since the majority of the supply temperatures for DOT comply with the set points of the control curve, the error margin should not affect the result significantly.

Also, as shown in Figure 12, the supply and return temperatures as encountered in this survey have been compared to theoretical supply and return temperature curves that have been developed based on an explicit expression by Kärkkäinen (2010). As can be observed, both supply and return temperature curves comply with the temperature curves by Kärkkäinen, and should for that reason be representative for each outdoor temperature category.

\section{Calculation of the Radiator Constant}

For the calculations of the normalized radiator constants, $\mathrm{K}_{\mathrm{rad}, \mathrm{n}}$, data for the specific heat usage in $\mathrm{kWh} / \mathrm{m}^{2}$,yr as well as total heated surface area, were utilized for each radiator system. However, the specific heat usage was inclusive of the DHW share and in order to calculate $\mathrm{K}_{\mathrm{rad}, \mathrm{n}}$ based on space heating utilization only the DHW heat usage was removed. The share was based on the total heat usage for the month of July and applied for the remainder of the year. This was because the heat usage in June and August were in general larger, which is probably due to the outdoor temperature during some nights in June and August giving rise to a heating need. The month of July may not however be entirely representative of the DHW heat usage due to many residents being absent for summer vacation, resulting in an overall smaller amount of DHW utilization that month.

The majority of the DHW shares was approximately $30 \%$ which corresponds to typical shares, but according to the operating engineers of Bostads AB Poseidon some of their buildings have a substantially larger DHW share than the average, whereas some are lower. However, not accounted for when calculating the DHW heat utilization share was the fact that the incoming DCW is colder in the winter compared to the month of July. For that reason, the energy utilization for DHW throughout the year has been underestimated.

Based on the hourly logarithmic mean temperature difference, $\Delta \mathrm{t}_{\ln }$, and the space heating utilization, represented by the thermal heat power output from the radiator, $\dot{\mathrm{Q}}_{\text {rad }}$, 
$\mathrm{K}_{\mathrm{rad}, \mathrm{n}}$ was calculated. In order to eliminate the outdoor temperatures for which the radiator circulation pump was stopped, temperature data measured for outdoor temperatures greater than the set point for pump stop were removed. However, for some of the systems there was no data available for the pump set point and for such cases the balance temperature was assumed based on the supply and return temperature plots.

For the instances where the radiator supply temperature sensor had recorded unrealistically high temperatures indicating radiator circulation pump stop, these values were eliminated in order to not contribute to heat being extracted when the pump most likely was turned off. Such measurements were removed, but this was accompanied with the possibility of removing values that in fact should have been part of the heat usage calculation and vice versa. The aforementioned leads to uncertainties in the amount of heat actually emitted by the radiator systems and since the calculation of $\mathrm{K}_{\mathrm{rad}, \mathrm{n}}$ is based upon the amount of heat emitted per hour, the uncertainties are carried over to the results of the radiator sizes.

\section{$5.4 \quad$ Future Work}

This study has surveyed the radiator system temperatures in existing multi-family residential buildings. However, in order to account for more types of radiator systems and other types of temperature demands by the DH customers it would also be beneficial to compare the temperatures of this study to those in single family households since these radiator systems serve a much smaller amount of radiators than those in multi-family buildings. It would also be useful to compare the temperatures in residential buildings to those present in commercial buildings since the thermal heat demand is different in these buildings.

The data in this study was obtained from only one housing company. It would therefore be interesting to compare the results of this survey to data from another housing company, either public or private. Since Bostads AB Poseidon is a large company with many buildings, they constantly work with reducing their buildings' energy usage. For that reason, the temperatures in the radiator systems encountered in buildings of another housing company may be different.

In this study, the only heat emitter surveyed was radiators since this is the most common heat emitter installed in Swedish multi-family buildings. However, for new constructions other types of heat emitters are found since different heating systems are usually installed, such as floor heating. It would therefore be valuable to survey the temperatures in such systems since they are usually lower than those in radiator systems. Only one floor heating system was encountered in the systems part of this study and was therefore disregarded since more data would be necessary to permit any comparisons.

For the calculations of the radiator sizes the assumptions for indoor temperature, $t_{\text {room, }}$ and radiator exponent, $n$, were fixed. A sensitivity analysis on the effects of other assumptions would be beneficial to conduct in order to investigate the variances from a different the indoor temperature other than $21^{\circ} \mathrm{C}$, as well as selecting a radiator with a different radiator exponent. 


\section{Conclusion}

In this study a survey of the radiator temperatures in multi-family residential buildings supplied by district heating in the city of Gothenburg, Sweden was conducted. Data from 109 radiator systems was surveyed and the average temperatures were found to be $64^{\circ} \mathrm{C}$ supply and $42^{\circ} \mathrm{C}$ return for design outdoor temperature (DOT) $-16^{\circ} \mathrm{C}$. However, the radiator supply temperatures encountered ranged from a maximum of $81^{\circ} \mathrm{C}$ to a minimum of $53^{\circ} \mathrm{C}$ for DOT and the corresponding return temperatures ranged from a maximum of $57^{\circ} \mathrm{C}$ to a minimum of $28^{\circ} \mathrm{C}$. The majority of the systems had supply temperatures between $60-70^{\circ} \mathrm{C}$ and it was shown that the temperature difference between supply and return increased with increasing supply temperatures.

The most important factors determining the temperature levels were shown to be radiator size and hydronic balancing of the radiator system. When relating the radiator heat transfer area to the building specific space heating demand it was shown that the majority of the buildings need some kind of renovation done to reduce the heating demand along with an increase of the radiator heat transfer surfaces, to enable lower operating temperatures. Hydronic balancing of the radiator systems was shown to increase the temperature difference in the radiator system by enabling a lower return temperature. The buildings constructed between 1950-1965 have the largest supply temperatures, which therefore are the most important to focus on in order to be able to reduce the radiator temperatures.

It would not be possible to reduce the district heating supply temperatures to $55^{\circ} \mathrm{C}$ already today, but the temperatures can be reduced to some extent, which depends on location in the DH system and time of the year. This would result in a smaller temperature difference between the DH supply and the radiator supply temperatures, which at present is substantial during large parts of the year.

For DOT, $-16^{\circ} \mathrm{C}$, it was shown that $8 \%$ of the radiator systems surveyed had a supply temperatures of $55^{\circ} \mathrm{C}$ or less. However, for a potential temperature reduction in the $\mathrm{DH}$ system to be possible, the majority of radiator systems surveyed need the heat transfer surface areas to be increased along with a reduction in specific space heating demand. For an outdoor temperature of $5^{\circ} \mathrm{C}$ or more all radiator systems surveyed operate with supply temperatures of $55^{\circ} \mathrm{C}$ or less. Based on this there is a potential of reducing the $\mathrm{DH}$ operating temperatures during parts of the year. 


\section{$7 \quad$ References}

Abel, E., Jagemar, L., \& Widén, P. (1995). Energiteknik - Litteratur till kursen Termodynamik och värmelära: Chalmers Tekniska Högskola.

Boverkets författningssamling BFS 2002:19 BBR 10, (2002).

Boverket. (2010a). Energi i bebyggelsen - tekniska egenskaper och beräkningar.

Boverket. (2010b). Teknisk status i den Svenska bebyggelsen - resultat från projektet BETSI.

Brange, L., Englund, J., \& Lauenburg, P. (2016). Prosumers in district heating networks - A Swedish case study. Applied Energy, 164, 492-500. doi:10.1016/j.apenergy.2015.12.020

Energimyndigheten. (2015). Energy statistics for multi-dwelling buildings in 2014.

Frederiksen, S., \& Werner, S. (1993). Fjärrvärme - Teori, teknik och funktion. Lund, Sweden: Studentlitteratur.

Frederiksen, S., \& Werner, S. (2013). District Heating and Cooling (First ed.).

Gadd, H., \& Werner, S. (2014). Achieving low return temperatures from district heating substations. Applied Energy, 136, 59-67. doi:10.1016/j.apenergy.2014.09.022

Gadd, H., \& Werner, S. (2015). Fault detection in district heating substations. Applied Energy, 157, 51-59. doi:10.1016/j.apenergy.2015.07.061

Gustafsson, J., \& Sandin, F. (2016). District heating monitoring and control systems. 241-258. doi:10.1016/b978-1-78242-374-4.00012-4

Incropera, F., Dewitt, D., Bergman, T., \& Lavine, A. (2005). Fundamentals of Heat and Mass Transfer.

Johansson, P.O. (2011). Buildings and District Heating - contributions to development and assessments of efficient technology. (PhD), Lund University.

Johnsson, J., Rossing, O., \& Wallentun, H. (2009). Produktion, distribution och kundcentraler.

Kärkkäinen, A. (2010). Gas-free filling of heating and cooling systems and balancing of radiator systems. (PhD), Aalto University.

Lauenburg, P. (2016). Temperature optimization in district heating systems. 223-240. doi:10.1016/b978-1-78242-374-4.00011-2

Lauenburg, P., \& Wollerstrand, J. (2014). Adaptive control of radiator systems for a lowest possible district heating return temperature. Energy and Buildings, 72, 132-140. doi:10.1016/j.enbuild.2013.12.011

Lund, H., Werner, S., Wiltshire, R., Svendsen, S., Thorsen, J. E., Hvelplund, F., \& Mathiesen, B. V. (2014). 4th Generation District Heating (4GDH). Energy, 68, 1-11. doi:10.1016/j.energy.2014.02.089

Myhren, J. A., \& Holmberg, S. (2009). Design considerations with ventilationradiators: Comparisons to traditional two-panel radiators. Energy and Buildings, 41(1), 92-100. doi:10.1016/j.enbuild.2008.07.014

Nilsson, G. (2007). Effektbesparing vid fjärrvärmeleverans. Svensk Fjärrvärme. 
Ommen, T., Markussen, W. B., \& Elmegaard, B. (2016). Lowering district heating temperatures - Impact to system performance in current and future Danish energy scenarios. Energy, 94, 273-291. doi:10.1016/j.energy.2015.10.063

Svensson, E. (2014). Industrial Energy Systems Compendium (E. Svensson Ed.). Göteborg, Sweden: Chalmers University of Technology.

Taesler, R. (1972). Klimatdata för Sverige.

Trüschel, A. (2002). Hydronic Heating Systems - The Effect Of Design On System Sensitivity. (PhD), Chalmers University of Technology.

Wollerstrand, J., Ljunggren, P., \& Johansson, P.-O. (2007). Optimal reglering av radiatorsystem. Svensk Fjärrvärme. 